\title{
Characterization of the Small Intestinal Lesion in Celiac Disease by Label-Free Quantitative Mass Spectrometry
}

\author{
Astrid E.V. Tutturen, ${ }^{\star \dagger}$ Siri Dørum,${ }^{*}$ Trevor Clancy, ${ }^{\ddagger}$ Henrik M. Reims, ${ }^{\S}$ Asbjørn Christophersen, ${ }^{\llbracket}$ Knut E.A. Lundin, ${ }^{\top \|}$ \\ Ludvig M. Sollid, ${ }^{* \pi /}$ Gustavo A. de Souza, ${ }^{\dagger * *}$ and Jorunn Stamnaes*
}

\begin{abstract}
From the Centre for Immune Regulation and Department of Immunology, ${ }^{*}$ University of Oslo and Oslo University Hospital-Rikshospitalet, Oslo, Norway; the Proteomics Core Facility ${ }^{\dagger}$ and the Department of Gastroenterology, ${ }^{\prime}$ Oslo University Hospital-Rikshospitalet, Oslo, Norway; the Department of Immunology, ${ }^{\ddagger}$ Institute for Cancer Research, Oslo University Hospital-Radiumhospitalet, Oslo, Norway; the Department of Pathology, ${ }^{\S}$ Oslo University Hospital, Oslo, Norway; the KG Jebsen Coeliac Disease Research Centre, "University of Oslo, Oslo, Norway; and The Brain Institute, ** Universidade Federal do Rio Grande do Norte, Natal-RN, Brazil
\end{abstract}

Accepted for publication

March 13, 2018.

Address correspondence to Jorunn Stamnaes, M.Pharm., Ph.D., Department of Immunology, Oslo University Hospital-Rikshospitalet, Sognsvannsveien 20, 0372 Oslo, Norway. E-mail: jorunn. stamnas@medisin.uio.no.

\begin{abstract}
Global characterization of tissue proteomes from small amounts of biopsy material has become feasible because of advances in mass spectrometry and bioinformatics tools. In celiac disease (CD), dietary gluten induces an immune response that is accompanied by pronounced remodeling of the small intestine. Removal of gluten from the diet abrogates the immune response, and the tissue architecture normalizes. In this study, differences in global protein expression of small intestinal biopsy specimens from CD patients were quantified by analyzing formalin-fixed, paraffin-embedded material using liquid chromatographymass spectrometry and label-free protein quantitation. Protein expression was compared in biopsy specimens collected from the same patients before and after 1-year treatment with gluten-free diet $(n=10)$ or before and after 3-day gluten provocation $(n=4)$. Differential expression of proteins in particular from mature enterocytes, neutrophils, and plasma cells could distinguish untreated from treated CD mucosa, and Ig variable region IGHV5-51 expression was found to serve as a CD-specific marker of ongoing immune activation. In patients who had undergone gluten challenge, coordinated up-regulation of wound response proteins, including the CD autoantigen transglutaminase 2, was observed. Our study provides a global and unbiased assessment of antigen-driven changes in protein expression in the celiac intestinal mucosa. (Am J Pathol 2018, 188: 1563-1579; https://doi.org/10.1016/j.ajpath.2018.03.017)
\end{abstract}

Global transcriptome and proteome quantification of diseased versus healthy tissue are attractive strategies to gain insight into disease mechanisms and discovery of biomarkers. Next-generation sequencing technology has boosted the field of transcriptome analysis. However, the correlation between mRNA transcript levels and protein expression levels is relatively poor. ${ }^{1,2}$ Thus, the importance of reliable characterization and quantification of cell and tissue proteomes are increasingly appreciated. Global labelfree protein quantification by use of mass spectrometry has in the recent years emerged as a sensitive tool for detection of differential protein expression. ${ }^{3}$ Also, formalin-fixed, paraffin-embedded (FFPE) tissue collected for routine pathology analysis can successfully be used for mass spectrometry analysis and identification and quantification of several thousand proteins. ${ }^{4-6}$

Celiac disease (CD) is a prevalent intestinal disorder that occurs in genetically susceptible individuals. The disease is

Supported by the South-Eastern Norway Regional Health Authority and the Research Council of Norway through its Center of Excellence funding scheme (project number 179573/V40). The Proteomics Core Facility is supported by a Norwegian Southeastern Health Organization Core Facility fund.

Disclosures: None declared.

Current address of A.E.V.T., Department of Molecular Cell Biology, Institute for Cancer Research, Oslo University Hospital, The Norwegian Radium Hospital, Oslo, Norway; of S.D., Norwegian Doping Control Laboratory, Oslo University Hospital, Oslo, Norway. 
Table 1 Characteristics of Celiac Disease Patients before and after Treatment

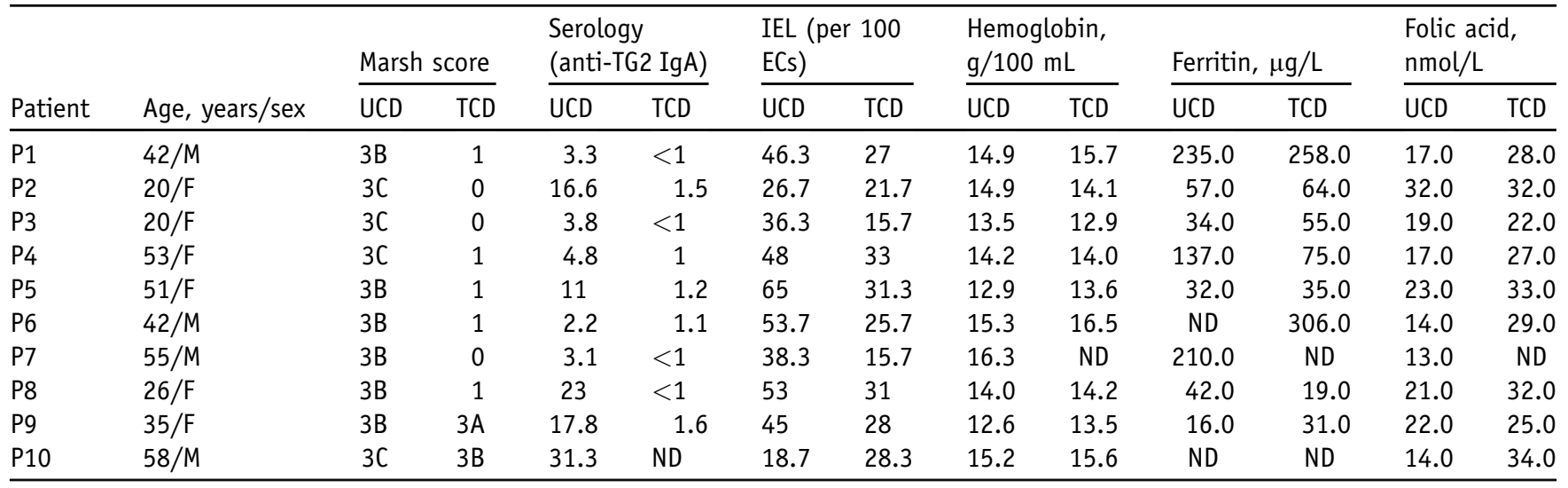

F, female; M, male; EC, enterocyte; IEL, intraepithelial lymphocyte; ND, not determined; TCD, treated celiac disease; TG2, transglutaminase 2; UCD, untreated celiac disease.

driven by a $\mathrm{CD} 4^{+}$T-cell response toward dietary gluten proteins. ${ }^{7}$ This results in inflammation in the small intestine, accompanied by tissue remodeling, villous blunting, and loss of intestinal surface area. The intestinal lesion is infiltrated with immune cells, in particular intraepithelial lymphocytes and $\operatorname{IgA}^{+}$plasma cells. ${ }^{8-10}$ On average, $10 \%$ of the plasma cells produce autoantibodies toward transglutaminase 2 (TG2), an endogenous enzyme that catalyzes posttranslational modification of gluten T-cell epitopes. ${ }^{11-13}$ Human leukocyte antigen-DQ-restricted $\mathrm{CD}^{+}{ }^{+} \mathrm{T}$ cells that recognize these gluten epitopes exhibit a proinflammatory phenotype and secrete high amounts of interferon (IFN)$\gamma \cdot{ }^{14-16} \mathrm{CD}$ patients also have increased numbers of $\mathrm{CD} 8^{+}$ intraepithelial $\mathrm{T}$ cells that contribute to tissue destruction and intestinal remodeling because these cells, by use of natural killer cell receptors, kill stressed enterocytes. ${ }^{17}$

Disease severity in CD can be graded according to the degree of histologic changes in the intestine and is often subclassified to six groups, ranging from Marsh 0 (M0) to Marsh 3C (M3C). ${ }^{18}$ M0 describes the normal histology. M1 describes the same overall villous structure with long villi and short crypts but $>25$ intraepithelial lymphocytes per 100 enterocytes. M2 has the same features but with crypt hyperplasia. M3A-C describes the range from partial to subtotal to total villous atrophy. Many of these morphologic changes are reversible, and removal of gluten from the diet often leads to recovery and normalization of the small intestinal architecture. ${ }^{19}$

The disease-specific adaptive immune response in $\mathrm{CD}$ is well characterized. This may be one of the reasons why few omics studies have been conducted on celiac intestinal tissue. $^{20-22}$ However, many questions still remain unanswered, and a priori knowledge on disease mechanisms should encourage bottom up transcriptome or proteome expression studies. Such efforts will generate data that can both support and supplement, or challenge, established knowledge. In this study, an in-depth analysis of the small intestinal celiac mucosa was performed, applying a quantitative liquid chromatography-tandem mass spectrometric (LC-MS/MS) proteomics approach, in which tissue from
FFPE blocks collected for routine histology assessment was analyzed. Protein expression levels were compared in biopsy specimens collected from the same patients before or after dietary intervention: First protein expression was compared in biopsy specimens collected from 10 patients with untreated CD (UCD) with biopsy specimens collected 1 year later after treatment with gluten-free diet [GFD; treated CD (TCD)]. Tissue from four TCD patients that developed morphologic changes on day 4 in response to 3-day gluten challenge was analyzed next. The data showed differential expression of proteins that agree with our current understanding of $\mathrm{CD}$ pathogenesis and also suggest that changes in protein expression may not always correlate with histology. Ig gene family use, which may serve as a disease-specific marker of immune activation, was identified. Patients subjected to 3-day gluten challenge displayed coordinated regulation of proteins indicative of acute wound response and tissue remodeling. This provides insight into the initial steps of intestinal remodeling in response to gluten in $\mathrm{CD}$.

\section{Materials and Methods}

\section{Patient Selection and Patient Material}

Fourteen DQ2.5 ${ }^{+}$CD patients were selected for post hoc analysis from two patient cohorts previously enrolled in research projects in our laboratory: In the first group, biopsy specimens collected from $10 \mathrm{CD}$ patients at the time of

Table 2 Characteristics of CD Patients Subject to 3-Day Gluten Challenge

\begin{tabular}{llll}
\hline & $\begin{array}{l}\text { Marsh score } \\
\text { Patient before gluten } \\
\text { years/sex }\end{array}$ & $\begin{array}{l}\text { Marsh score } \\
\text { d4 aftenge }\end{array}$ & $\begin{array}{l}\text { of gluten challenge } \\
\text { chas }\end{array}$ \\
\hline B & $47 / F$ & 1 & $3 \mathrm{~A}$ \\
C & $31 / \mathrm{F}$ & $3 \mathrm{~A}$ & $3 \mathrm{~B}$ \\
D & $59 / \mathrm{F}$ & 2 & $3 \mathrm{~A}$ \\
E & $53 / \mathrm{F}$ & 0 & $3 \mathrm{~B}$ \\
\hline
\end{tabular}

F, female; d0, day $0 ;$ d4, day 4 . 
diagnosis (UCD) were compared with biopsy specimens collected 1 year later after treatment with GFD (TCD) (A. Christophersen et al, unpublished data). All patients were classified as M3 at the time of diagnosis, and most recovered to M0-1 1 year later (patients P1 to P10) (Table 1). The second group of patients consisted of four TCD patients who developed histologic changes in response to a 3-day gluten challenge. ${ }^{23}$ Biopsy material collected on day 0 before challenge and biopsy specimens collected on day 4 after challenge were analyzed (patients $B$ to E) (Table 2). Material from duodenal biopsy blocks collected for histology assessment was used in this study. For patients P1 to P10, selected clinical parameters assessed at the time of diagnosis and after 1-year follow-up are reported (Table 1) (A. Christophersen et al, unpublished data). All patients had given informed and written consent, and the use of material was approved by Regional Committee for Medical and Health Research Ethics (REK 2010/2720).

\section{Preparation of FFPE Tissue Section Digests}

Fifteen sections ( $5 \mu \mathrm{m}$ thick) were cut from each FFPE biopsy block and collected in a tube $(1.5 \mathrm{~mL}$; Eppendorf, Hamburg, Germany). Paraffin was removed by the following procedure. Paraffin Removal Reagent (1 mL; BiOstick; MO BIO Laboratories, Qiagen, Carlsbad, CA) was added and incubated for 3 minutes at $55^{\circ} \mathrm{C}$ with gentle agitation. The samples were centrifuged at $14,000 \times g$ for 5 minutes, and the supernatant was removed. Xylene $(1 \mathrm{~mL}$; AnalR Normapur, VWR Chemicals, Radnor, PA) was added, and the previous step was repeated. Ethanol (absolute, $1 \mathrm{~mL}$; AnalR Normapur, VWR Chemicals) was added and incubated for 5 minutes at room temperature with gentle agitation before centrifugation as above and removal of supernatant. The purification step with ethanol was repeated, but incubation time was 1 minute. Traces of ethanol were removed from the samples by incubation in a vacuum drier. For protein extraction, the sample tissues were dissolved in $20 \mu \mathrm{L} 0.2 \%$ ProteaseMax Surfactant (trypsin enhancer; Promega, Madison, WI) in $50 \mathrm{mmol} / \mathrm{L} \mathrm{NH}_{4} \mathrm{HCO}_{3}$, and $73.5 \mu \mathrm{L} 50 \mathrm{mmol} / \mathrm{L} \mathrm{NH}_{4} \mathrm{HCO}_{3}$ was added. The samples were sonicated in water bath for 60 minutes and further incubated at $98^{\circ} \mathrm{C}$ for 90 minutes on a heating block. The samples were quickly spun down every 10th minute to avoid liquid accumulation in the lid. The samples were slowly cooled down to room temperature and frozen at $-20^{\circ} \mathrm{C}$ overnight. The samples were thawed and sonicated in a water bath for 60 minutes. Protein concentration was measured using DirectDetect (Millipore, Merck, Darmstadt, Germany). For trypsin digestion, the whole extracts were used (protein concentrations ranged from 20 to $37.4 \mu \mathrm{g}$ ), and lysozyme (from chicken, egg white; BioUltra lypholyzed powder, $>98 \% ;>40.000 \mathrm{U} / \mathrm{mg}$ protein) was spiked in to a final concentration of $0.2 \%(\mathrm{w} / \mathrm{w})$. For enzymatic digestion, $1 \mu \mathrm{L} 1 \%$ ProteaseMax Surfactant and $0.5 \mu \mathrm{g}$ trypsin were added and incubated at $37^{\circ} \mathrm{C}$ in a wet chamber overnight. ProteaseMax Surfactant was degraded by adding trifluoroacetic acid to a final concentration of $0.5 \%$, and the samples were vortex mixed and incubated for 5 minutes at room temperature before centrifuging for 10 minutes at $14,000 \times g$.

\section{LC-MS/MS Analysis}

Before LC-MS/MS analysis, the samples were desalted by reversed-phase chromatography using $\mathrm{C} 18$ microcolumns prepared by stacking three layers of C18 Empore Extraction Disk (Varian, St. Paul, MN) into 200- $\mu$ L pipette tips. For samples from patients P1 to P10 (Table 1), reference peptides (150 fmol; MassPREP Digestion Standard Mix 1; Waters, Milford, MA) were spiked into each sample, before sample volume was adjusted to $14 \mu \mathrm{L}$ using $0.1 \%$ formic acid. Samples were analyzed in three technical replicates on a Q Exactive hybrid quadropole-orbitrap plus (Thermo Fisher Scientific, Waltham, MA) interfaced with an EASY-nLC 1000 (Thermo Fisher Scientific). Peptides were separated on a 50-cm EASY Spary PepMapRSLC column (C18, $2 \mu \mathrm{m}, 100$ $\AA$, 75- $\mu \mathrm{m}$ inner diameter; Thermo Fisher Scientific) using a 300 -minute gradient: $2 \%$ to $19 \%$ B in 19 minutes, $19 \%$ to $22 \%$ $\mathrm{B}$ in 156 minutes, and $22 \%$ to $35 \% \mathrm{~B}$ in 125 minutes (solution A: water with $0.1 \%$ formic acid; solution B: acetonitrile with $0.1 \%$ formic acid). The mass spectrometer was operated in a data-dependent mode, with top $10 \mathrm{MS} / \mathrm{MS}$ scans using a MS scan range of 400 to $1200 \mathrm{~m} / z$. The following parameters for MS scan were applied: resolution, 70.000 at $\mathrm{m} / \mathrm{z}$, 200; AGC target, 3e6; and maximum IT, 100 milliseconds. The MS/MS scan was performed using the following parameters: resolution, 17.500; AGC target, 1e5; maximum IT, 100 milliseconds; isolation window, $2.0 \mathrm{~m} / \mathrm{z}$; NCE, 25; underfill ratio, $1.0 \%$; intensity threshold, $1.0 \mathrm{e} 4$; and dynamic exclusion, 30.0 seconds. Samples from patient B to E (Table 2) were analyzed by similar conditions as described above; the instrument was an Q Exactive hybrid quadropole-orbitrap (Thermo Fisher Scientific), and peptide separation was performed on a 25-cm EASY Spray PepMapRSLC column (C18, $2 \mu \mathrm{m}, 100 \AA$, $75-\mu \mathrm{m}$ inner diameter; Thermo Fisher Scientific) using a 300 -minute gradient, with $2 \%$ to $30 \% \mathrm{~B}$ in $300 \mathrm{mi}-$ nutes. Isolation window was set to $3.0 \mathrm{~m} / \mathrm{z}$ for MS/MS scans.

\section{Database Search}

Protein identification and label-free quantitation were performed using the MaxQuant software package version 1.5.1.2. ${ }^{24}$ MS and MS/MS spectra were searched by the Andromeda search engine ${ }^{25}$ against the UniProtKB FASTA database for the human proteome 85,915 entries including isoforms and canonical sequences; downloaded from $h t t p: / /$ www.UniProt.org, October 2014) in addition to a FASTA database of spiked-in proteins for patients P1 to P10. The following parameters were applied: enzyme: trypsin with no proline restriction; variable modifications: deamidation, oxidation, acetylation (protein N-term), Gln-pyro, and pyroGlu. The first search was performed with mass tolerance of $20 \mathrm{ppm}$ for precursor ion, and after recalibration, a 6-ppm 


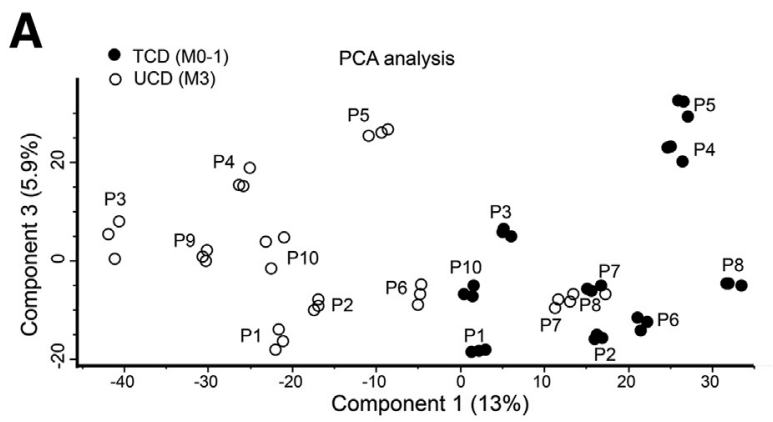

D
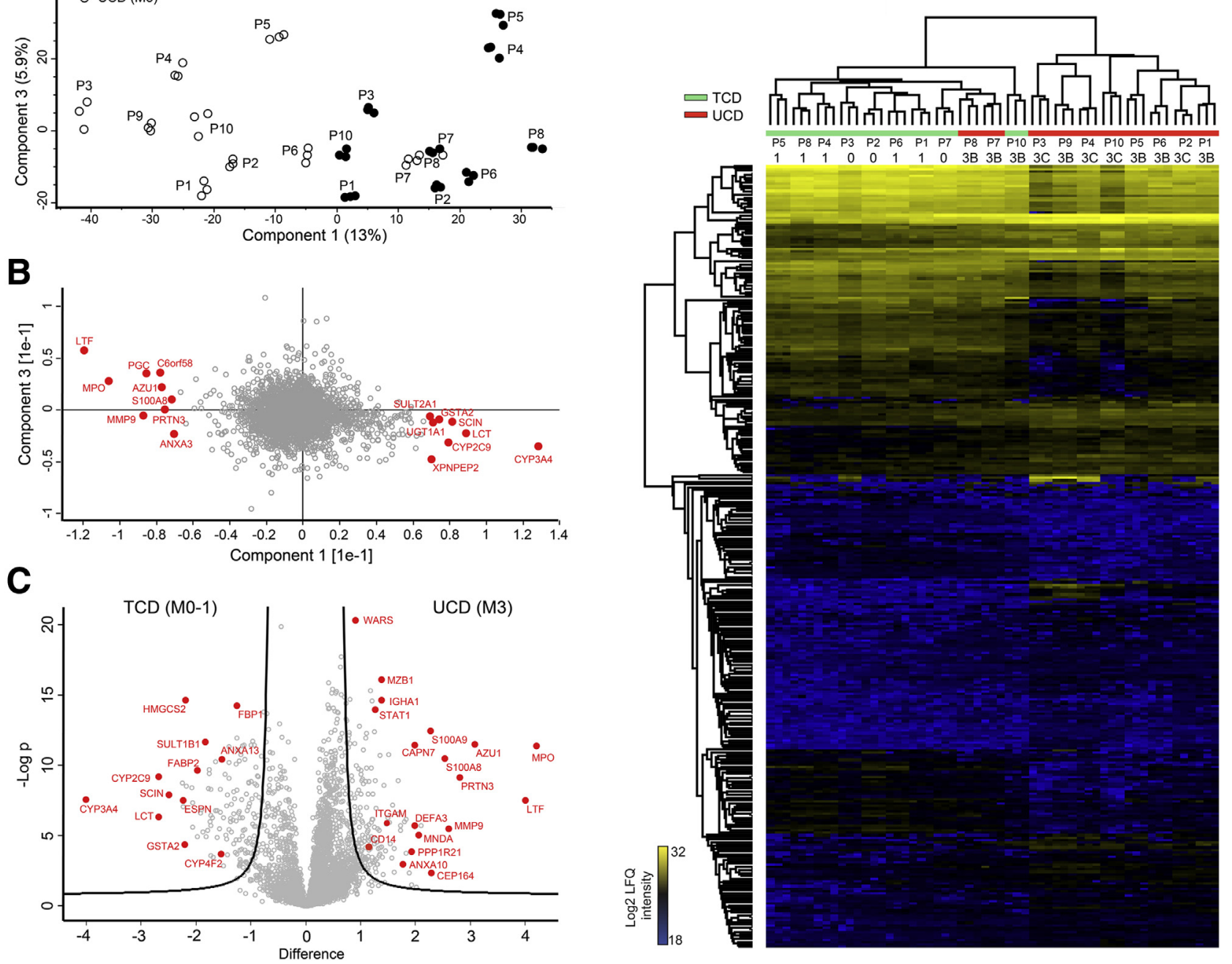

Figure 1 Differential protein expression in untreated celiac disease (UCD) versus treated celiac disease (TCD) mucosa. A: Principal component analysis (PCA) of log2-transformed LFQ intensities of all identified proteins. UCD samples are shown as open circles, and TCD samples are shown as filled circles. Technical replicates group together. B: Scatter plot of all proteins loaded for principal component analysis, where selected proteins that contribute strongly to separation of TCD and UCD are highlighted in red. C: Differentially expressed proteins in UCD (M3) compared with TCD (M0-1) mucosa visualized as volcano plot (two-sample $t$-test, false-discovery rate $<0.01)$. The line defining the outliers is limited by the $P$ value in the $y$ axis and the S0 value $(0.5)$ in the $x$ axis. Selected proteins with strong differential expression are indicated in red. D: Hierarchical clustering of log2-transformed LFQ intensities of differentially expressed proteins separates UCD and TCD (yellow $=32$, and blue $=18$ ). $\mathrm{P}$, patient.

tolerance was used in the main search; mass tolerance for fragment ions was set to $20 \mathrm{ppm}$. Minimal unique peptides were set to 1 , and a false-discovery rate of 0.01 was used in all instances. For identification, match between runs was enabled, and the MaxQuant label-free quantification (LFQ) algorithm with a minimum ratio count of one was used for quantification. Data from patient P1 to P10 (Table 1) and patient B to E (Table 2) were analyzed separately. For Ig gene identifications, data from P1 to P10 were searched against a FASTA database generated from amino acid sequences of human Ig families obtained from the International ImMunoGeneTics Information System database ${ }^{26,27}$ and the FASTA database for spike-in proteins using the same parameters as above. The mass spectrometry proteomics data have been deposited to the ProteomeXchange
Consortium via the PRIDE partner repository with the data set identifier PXD008992. ${ }^{28}$

\section{Statistical Analysis}

Perseus software version 1.5.0.31 (MaxPlank Institute of Biochemistry, Martinsried, Germany) was used to perform statistical analysis of LFQ intensities. Proteins considered by MaxQuant to be possible contaminants, hits from reverse sequences, or those only identified by site were removed from the list of identifications for all data sets before statistical analysis. Protein groups identified by one peptide and quantified by one LFQ ratio were not excluded from downstream analysis. Proteins highlighted in Results and Discussion were quantified by LFQ $>1$. Biopsy specimens were grouped in 
A

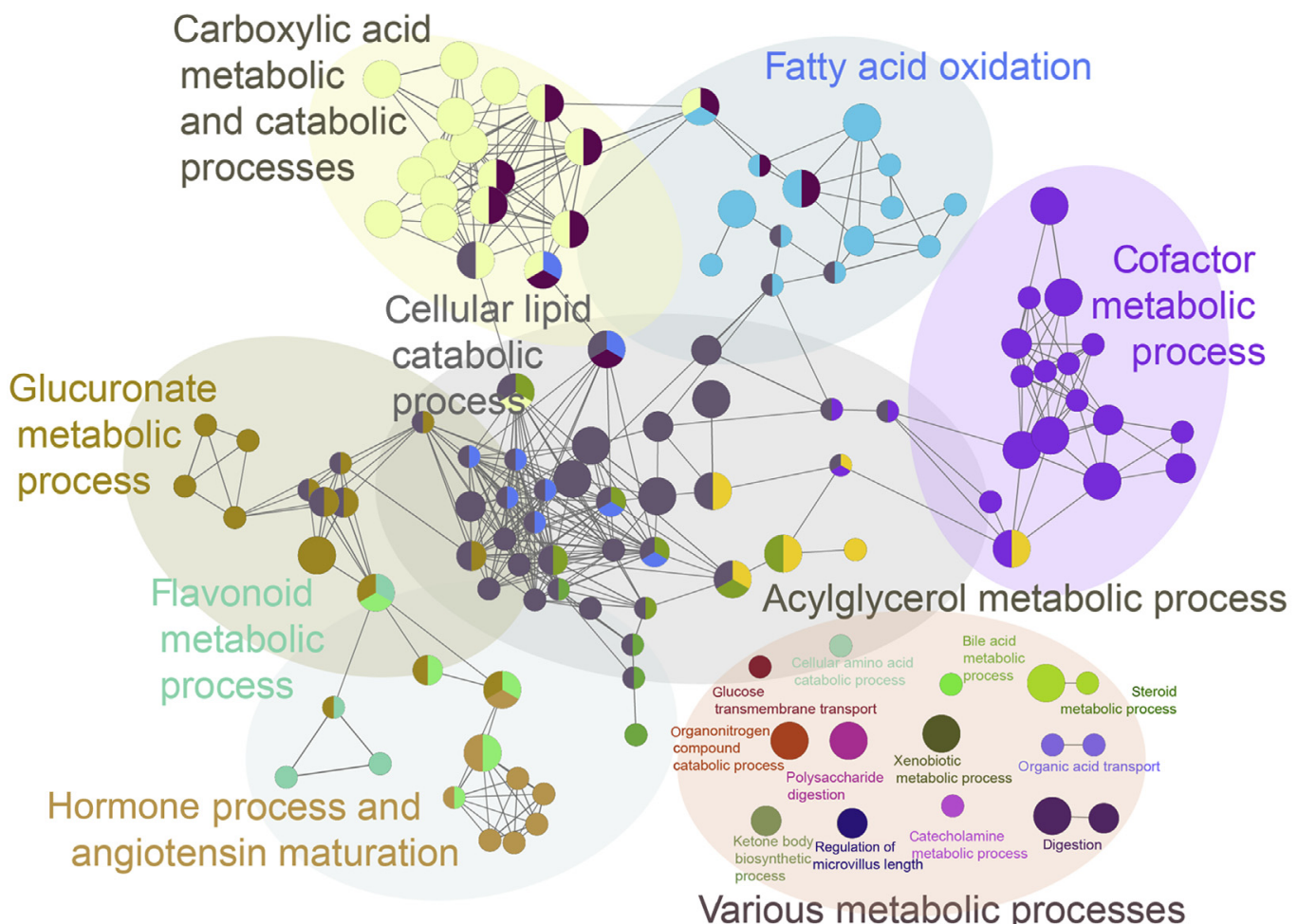

B

CYP3A4

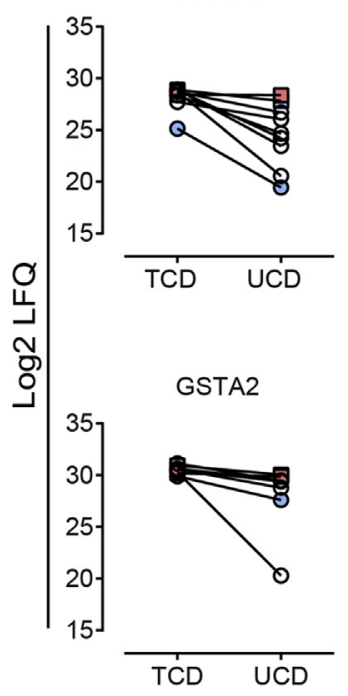

CYP2C9

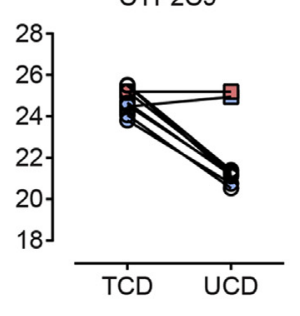

SCIN

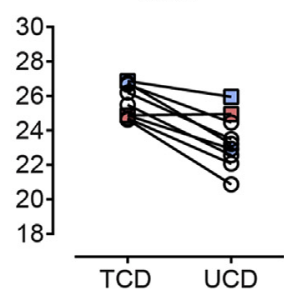

LCT

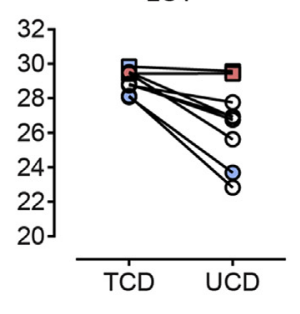

VIL1

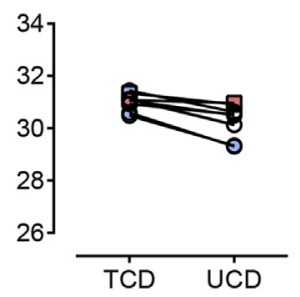

FABP2

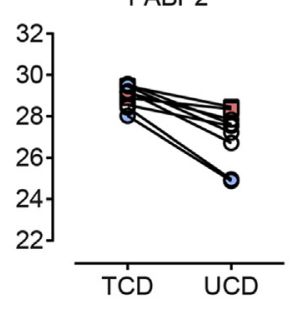

ESPR1

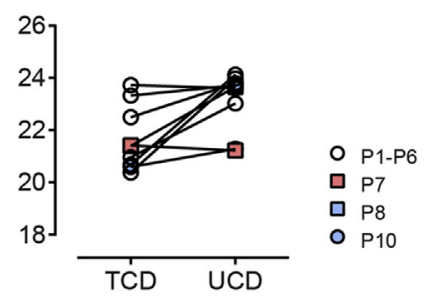

Figure 2 Proteins involved in nutrient metabolism and enterocyte function show reduced expression in untreated celiac disease (UCD) mucosa and increased expression in treated celiac disease (TCD) mucosa. A: Gene Ontology (G0) biological process enrichment analysis of proteins significantly increased in TCD mucosa. Each pathway is shown as a node, and node size reflects enrichment $P$ value. Groups are formed on the basis of the number of shared proteins between the pathways ( $>50 \%$ ). For most groups, the G0 term with the lowest $P$ value is boldfaced. Nodes with split colors indicate processes that fit to several groups. Edges indicate that proteins are shared between the processes (nodes). B: Comparison of log2-transformed LFQ intensities for selected proteins before (UCD) or after (TCD) gluten-free diet for all patients (P), except P9.

two categories: TCD or UCD for P1 to P10 or before and after for patients $\mathrm{B}$ to $\mathrm{E}$. An imputation approach was used to replace the zero values by randomly generated values selected accordingly to the normal distribution of the data to simulate the distribution of low abundant proteins. $^{29}$ Principal component analysis was done on $\log 2$ transformed LFQ intensities after imputation of zero values. $t$-Test was performed using a $P<0.01$ as threshold for $\mathrm{P} 1$ to $\mathrm{P} 10$ and $P<0.05$ for patient $\mathrm{B}$ to $\mathrm{E} ; \mathrm{S} 0=0.5$, and further false-discovery rate correction was performed using a permutation-based method, allowing 250 randomizations for both groups. Volcano plots were generated using the same parameters. Sample hierarchical clustering was done in Perseus on $t$-test significant proteins using $\log 2$ transformed LFQ values, where zero 
A

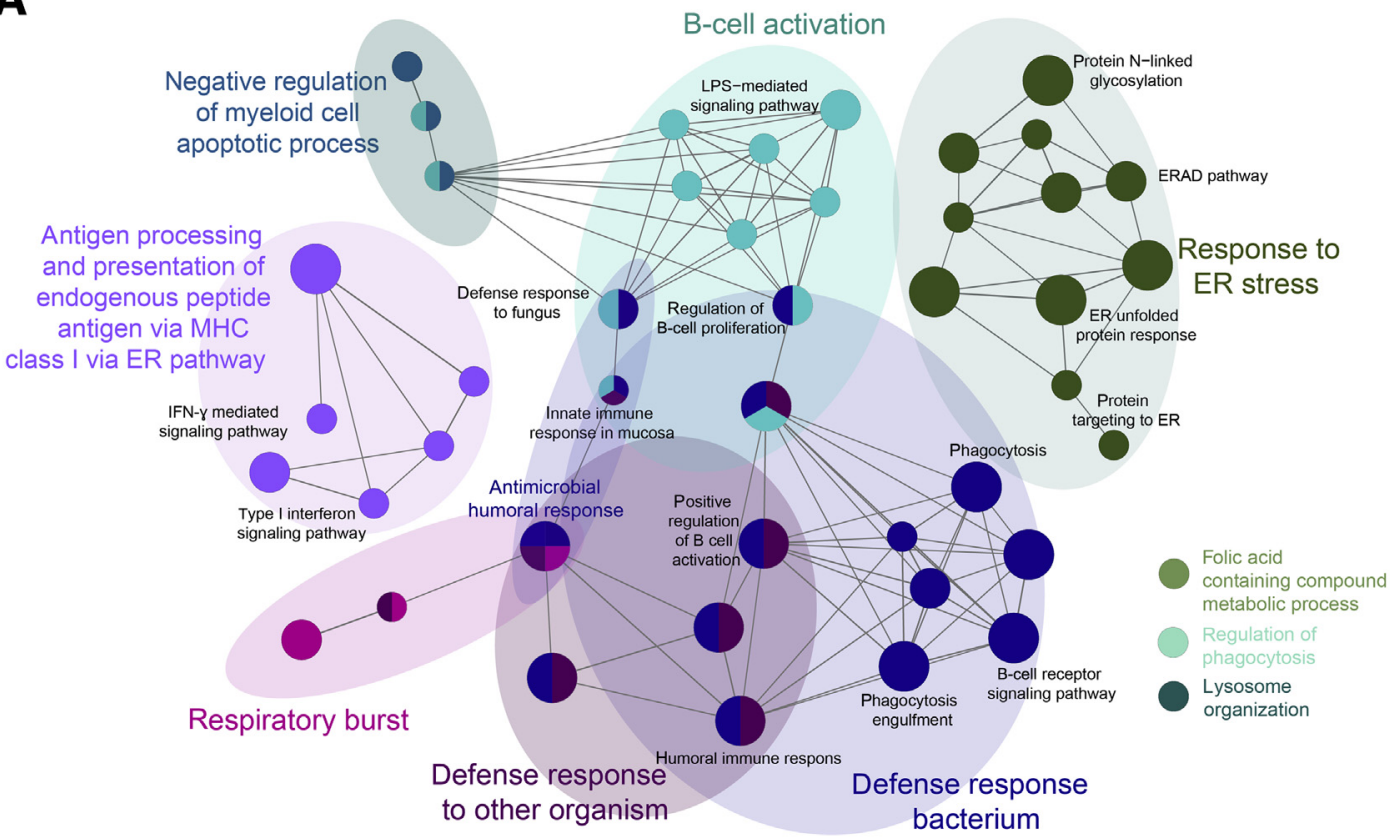

Immunoglobulin gene family identifications

B

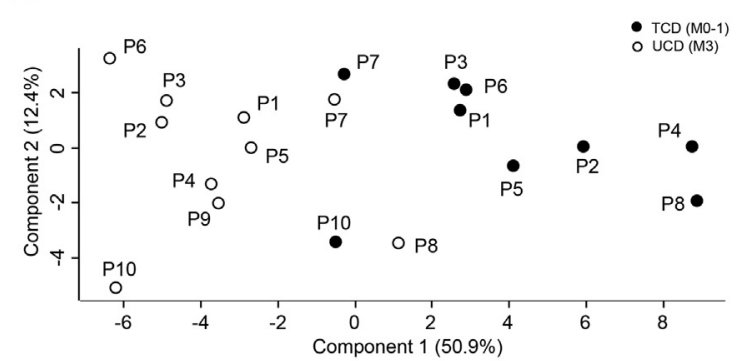

D

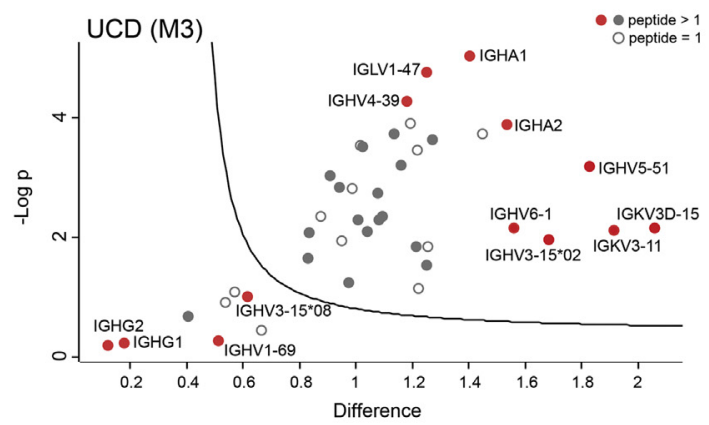

C

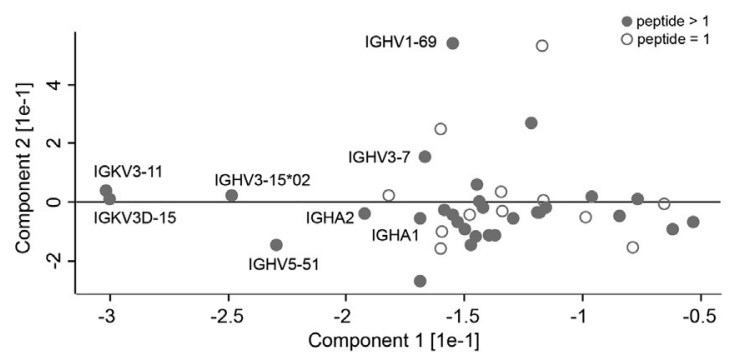

$\mathbf{E}$

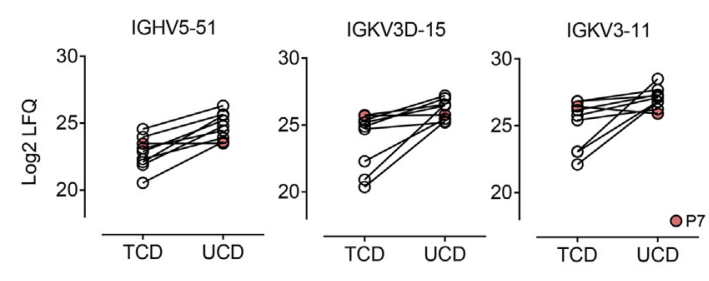

Figure 3 Increased expression of plasma cell-related processes and Igs in untreated celiac disease (UCD) mucosa. A: Gene Ontology biological process enrichment analysis of proteins that significantly increased UCD (M3) mucosa. Of 143 annotated genes, 88 are represented in enriched biological processes. These can broadly be divided into immune response processes and protein synthesis and endoplasmic reticulum (ER) stress. B: Principal component analysis of log2-transformed LFQ intensities of identified Ig family members from MaxQuant search against dedicated Ig database. UCD samples are shown as open circles, and treated celiac disease (TCD) samples are shown as filled circles. Median of technical replicates is used. C: Scatter plot of all proteins loaded for principal component analysis. Proteins identified from one or more than one peptide are shown as open or filled circles, respectively. The gene name of the leading razor protein is shown. D: Differential expression of Igs in UCD (M3) compared with TCD (M0-1) mucosa visualized as volcano plot (two-sample $t$-test, false-discovery rate $<0.05$, S0 $=0.5$ ). Proteins identified by one or more than one peptide are shown as open or filled (gray and red) circles, respectively. Selected proteins are shown in red. Allotypes are indicated for IGHV3-15*02 and *08 because both were identified from two unique peptides of comparable quality (data not shown). E: Comparison of log2-transformed LFQ intensities for selected Igs before (UCD) or after (TCD) gluten-free diet. Patient (P) 7 is shown in red. ERAD, endoplasmic-reticulum-associated protein degradation; IFN- $\gamma$, interferon- $\gamma$; LPS, lipopolysaccharide; MHC, major histocompatibility complex. 
values were replaced by imputation as described above, choosing euclidian distance for row tree generation and Spearman correlation for column tree generation. Colors indicate $\log 2$ LFQ intensity. Protein intensity graphs show median values of $\log 2 \mathrm{LFQ}$ intensities after imputation of zero values. For Ig gene identifications, contaminants were filtered out as above and only proteins with valid values in at least $50 \%$ of TCD or UCD groups were included. Imputation of zero values was done on the basis of total matrix expression after $\log 2$ transformation. Protein identification from the spike-in database and two Ig protein groups assigned to open reading frames were removed before statistical analysis. Median values for sample triplicates were used for principal component analysis, and $t$-test comparison was visualized as volcano plot (two-sample $t$-test, $P<0.05, \mathrm{~S}=0.5$ ).

\section{Bioinformatic Analysis}

Cytoscape $^{30}$ version 3.3.0 was used with the plug-in ClueGO $^{31}$ to address enrichment of Gene Ontology (GO) biological processes. The gene list corresponding to proteins with reduced or increased expression ( $t$-test significant, from Perseus) was used. If more than one gene name was given for the identified protein group, the first gene name was selected. Some protein identifications that were not assigned to unique genes (eg, Ig entries) were not included in enrichment analysis. Default settings were used. GO Term fusion was chosen, and only pathways enriched by $P<0.05$ were shown. Grouping was based on $\kappa$ score, with initial group size of 1 and $50 \%$ genes or terms for group merge. Networks were visualized in CytoScape and further color coded using Adobe Illustrator version CS5.1. Proteins up-regulated in P1 to P10 were also searched for GO Reactome pathway enrichment.

\section{Protein-Protein Interaction Network Analysis}

For patient P1 to P10 (UCD versus TCD), a custom proteinprotein interaction (PPI) network was built by selecting seed genes that were $t$-test significant from Perseus $(P<0.01)$ and allowing those seed genes to generate PPI networks from an integrated database of protein interactions. ${ }^{32}$ Each PPI in the network had at least one PubMed citation, was experimentally validated, and was a physical binding interaction. Only protein interaction neighbors detected in the proteomics data set were allowed to form interactions in the PPI network generation. A filter was applied whereby only proteins annotated to the GO term response to cytokine (GO:0034097) were allowed to be included in the PPI network. The network was then visualized and annotated using the Cytoscape version 3.3.0, and all proteins were labeled as increased or decreased in UCD versus TCD on the basis of the fold change in expression, as calculated from the $t$-test analysis in Perseus. Proteins present in the GO terms response to type I interferon (GO: 0034340), response to IFN- $\gamma$ (GO: 0034341), or response to tumor necrosis factor (GO: 0034612) were color coded as indicated.
For patient B to E (before and after 3-day challenge), PPI analysis was performed using STRING ${ }^{33} t$-Test significant up-regulated proteins $(84 ; P<0.05)$ from Perseus were analyzed, resulting in 83 nodes (proteins) and 135 edges (interactions). The network was exported and further color coded in Adobe Illustrator CS5.1. Nodes (proteins) with no edges (interactions) were removed from the network.

\section{Immunoenzyme Staining and Estimation of Cell Densities}

Tissue sections from FFPE biopsy blocks of five patients (P1, P2, P5, P6, and P10; UCD and TCD) were subjected to immune-enzyme staining to enumerate $\mathrm{CD} 15$, myeloperoxidase (MPO), and calprotectin expressing cells. Sections (3 $\mu \mathrm{m}$ thick) were stained using the Dako EnVisionTM Flex + System (K8012; Dako, Glostrup, Denmark) and the Dako Autostainer. Deparaffinization and epitope retrieval was performed using PT-Link (Dako) and EnVisionTM Flex target retrieval solution. Endogeneous peroxidase was blocked using $0.3 \%$ hydrogen peroxide for 5 minutes. Sections were incubated for 30 minutes at room temperature with primary antibodies (rabbit polyclonal anti-calprotectin, 1:10,000; gift from Inge Dale, Calpro, Oslo, Norway), rabbit polyclonal anti-MPO (1:1000, A0398; Dako), or mouse monoclonal IgM anti-CD15 (1:50, clone Carb-3; Dako), followed by 15 -minute incubation with EnVision FLEX $^{+}$rabbit or mouse linker. Sections were incubated with secondary antibodies for 30 minutes at room temperature, followed by 393-diaminobenzidine tetrahydrochloride for 10 minutes and counterstaining using hematoxylin.

Stained sections were scanned (Pannoramic MIDI; 3DHistech, Budapest, Hungary), exported, and analyzed using the QuPath software version 0.1.2, ${ }^{34}$ blinded to patient number and diagnosis. Four to six representative regions of lamina propria (ranging from 30,000 to $90,000 \mu \mathrm{m}^{2}$ ) were annotated per slide, spanning from the subepithelial basement membrane to the muscularis mucosae when possible. 393Diaminobenzidine tetrahydrochloride-positive cells were counted using the positive cell detection tool. Only cells that were considered highly positive were counted, and positive selections were manually verified. Reported values represent mean values from all counted regions. Representative regions of CD15 staining from two patients were exported to ImageJ software version 1.51g (NIH, Bethesda, MD; http://imagej. nih.gov/ij) and saved as TIF.files.

\section{Multicolor Immunofluorescence Staining}

FFPE tissue sections ( $3 \mu \mathrm{m}$ thick) of three patients (P6, P5, and $\mathrm{P} 2$ ) were dewaxed and subjected to antigen retrieval by heat $\left(95^{\circ} \mathrm{C}\right.$ in water bath for 20 minutes) using Dako antigen retrieval solution (Dako). Tissue sections were blocked for 30 minutes in $1.25 \%$ IgG-free bovine serum albumin (Jackson Immunoresearch, West Grove, PA) at room temperature. Primary antibodies were applied overnight at $4^{\circ} \mathrm{C}$, 
A

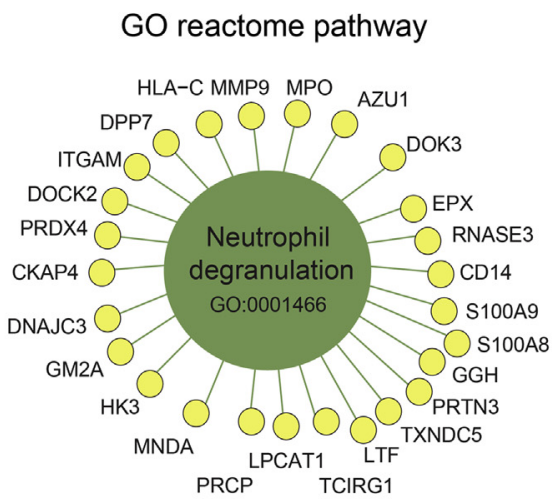

B

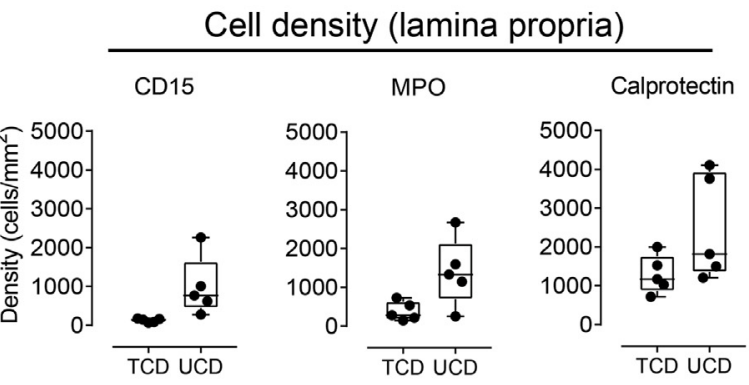

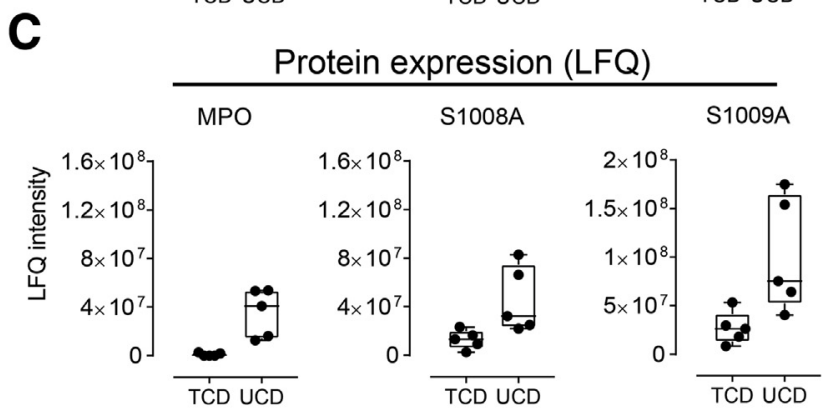

D

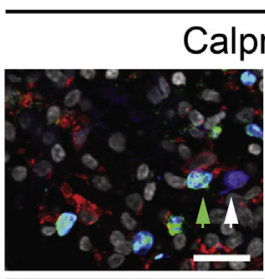

Untreated CD

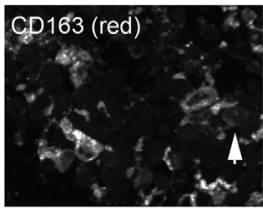

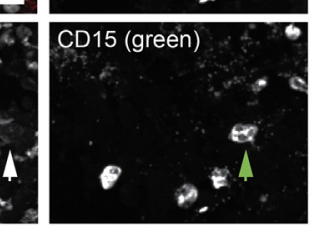

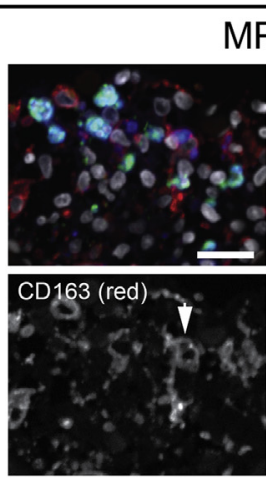

MPO

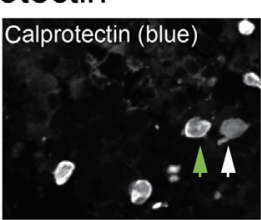

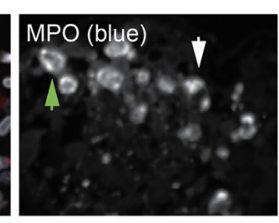

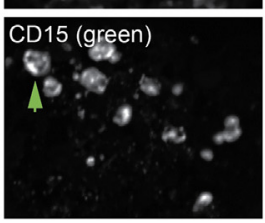

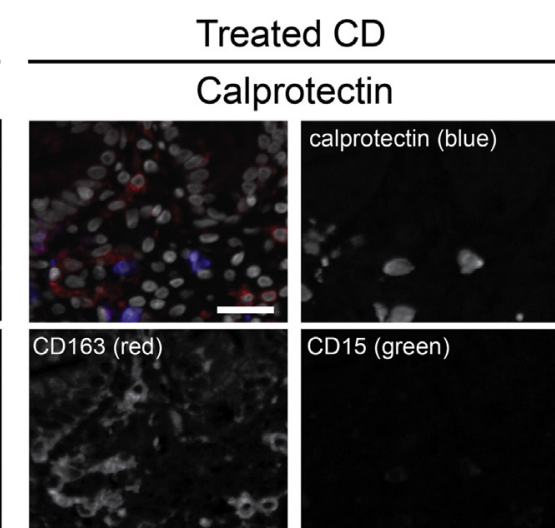

Figure 4 Increase of neutrophil- and monocyte-derived cells in untreated celiac disease (UCD) mucosa is reflected in the proteome expression profile. A: Twenty-six of the significantly increased proteins in UCD mucosa map to the Gene Ontology Reactome pathway neutrophil degranulation. B: Density of CD15-, myeloperoxidase (MP0)-, and calprotectin-positive cells in the duodenal lamina propria of five patients comparing UCD and treated celiac disease (TCD samples). Data points represent mean counts for individual patients, and box plots denote minimum, maximum, and median values in the group. C: LFO intensity values for MP0 and calprotectin (S1008A and S1009A) for the same patients as shown in B. Data points represent values from individual patients, and box plot denotes minimum, maximum, and median values in the group. D: Representative images showing immunofluorescence costaining for CD15, CD163, and calprotectin or MPO. Merged images were pseudocolored in ImageJ version 1.5.1d, and nuclei are shown in gray. Single-channel images are shown in gray scale. Arrows denote single- or double-positive cells, representing neutrophil-derived (green arrows) and monocyte-derived (white arrows) cells. Scale bar $=20 \mu \mathrm{m}(\mathbf{D}) . \mathrm{CD}$, celiac disease.

followed by secondary antibodies for 90 minutes at room temperature. The primary antibodies against CD15, MPO, and calprotectin were the same as used for immunoenzyme staining. In addition, anti-CD163 (mouse monoclonal $\mathrm{IgG}_{1}$, 1:1000, clone 10D6; Dako) was used. Secondary antibodies were donkey-anti-mouse-IgM-A488 (115-545-075; Jackson ImmunoResearch), goat-anti-mouse- $\operatorname{IgG}_{1}-\mathrm{Cy} 3$, and goat-anti-rabbit-A647 (both from Southern Biotechnology Associates, Birmingham, AL). Nuclei were counterstained with DAPI, and slides were mounted with homemade poly(vinyl alcohol). Images were acquired with an Olympus Fluoview FV1000 laser scanning confocal microscope
(Olympus, Tokyo, Japan) using an Olympus UPlanAPO 20/ 0.8 oil lens (Olympus) and the FV10-ASW software version 4.2 (Olympus). Images were processed and assembled using FIJI/ImageJ. ${ }^{35,36}$

\section{Results}

Comparison of Protein Expression in UCD versus TCD Mucosa

FFPE tissue sections were analyzed from biopsy blocks of 10 patients with $\mathrm{CD}$ by LC-MS/MS, comparing biopsy 
specimens collected at the time of diagnosis (UCD) with biopsy specimens collected 1 year later, after treatment with GFD (TCD). Proteins were quantified using the LFQ algorithm implemented in the MaxQuant software, which allows for comparison of samples analyzed in individual LC-MS runs. ${ }^{24,37}$ The normalization was initially verified by spiking all samples with four different predigested proteins and one intact protein. The spiked-in proteins showed comparable LFQ intensities for all samples, except for patient P9 after treatment (Supplemental Figure S1). However, total protein recovery for this sample was also extremely low (data not shown), and it was therefore removed from the data set. In total, 4711 proteins were identified (Supplemental Table S1). Principal component analysis on $\log 2$ transformed LFQ intensities of all proteins separated the data according to UCD or TCD, except for two UCD samples (P7 and P8) that clustered as TCD (Figure 1A). From the underlying protein distribution along component 1 (Figure 1B), it can be seen that proteins likely deriving from neutrophils and monocytes [eg, lactotransferrin (LTF) and MPO] and proteins likely deriving from mature enterocytes [eg, CYP3A4 and lactase (LCT)] drive this clustering (Figure 1B). Thus, samples from UCD and TCD mucosa can be distinguished on the basis of the global proteome expression level. Comparing the 10 UCD samples with nine TCD samples, differential expression of 322 proteins ranging from 1.6- to 18.2-fold difference in expression (two-sample $t$-test, false-discovery rate $<0.01$ ) was found. A total of 175 proteins were found with higher expression in UCD, and 147 proteins were found with higher expression in TCD (Supplemental Table S2), as visualized by a volcano plot (Figure 1C). Hierarchal clustering of $\log 2$ transformed LFQ intensities for these proteins showed grouping according to TCD or UCD, again with the exception of the P7 and P8 UCD samples (Figure 1D). These two patients differed from the other UCD M3 patients on the protein level, despite similar Marsh classification. In the paired material, one patient (P10) did not recover to M0-1 but remained M3B after treatment. This was reflected by longer distance from the remaining TCD M0-1 samples in the dendogram (Figure 1D).

\section{Processes Related to Enterocyte Function Are Enriched in TCD Mucosa}

To address whether the differentially expressed proteins derive from one or more up-regulated biological processes, GO biological process enrichment analysis was performed using the ClueGO application in Cytoscape. ${ }^{31}$ Analysis of 144 unique genes from the 147 proteins with increased expression in TCD showed enrichment for multiple processes related to nutrient metabolism and enterocyte function (Figure 2A). Reduced expression of these proteins in UCD agrees with the histologic appearance of M3 with villous blunting, crypt hyperplasia, and reduced numbers of mature enterocytes. Proteins annotated to the enriched processes are listed in Supplemental Table S3. Log2 transformed LFQ intensities of selected enterocyte-derived proteins for all patients, except $\mathrm{P} 9$, were compared, and it was found that Villin, which is expressed in all enterocytes, increased only modestly on treatment (TCD). In contrast, a clear increase in expression for enterocyte function-related proteins, including CYP3A4, CYP2C9, LCT, and fatty acid binding protein 2 (FABP2), was observed (Figure 2B). Thus, the biggest difference between the groups is attributable to difference in enterocyte maturation status rather than total enterocyte number, as assessed from Villin (VIL1). Patient P7 and P8 UCD samples showed high expression of enterocyte-derived proteins, in particular for CYP2C9, despite classification as M3B (Figure 2B). This likely explains why these samples failed to cluster with the other UCD patients (Figure 1, A and D). No available clinical parameters differentiated these subjects from the remaining cohort (Table 1 and data not shown). It is unclear whether these patients initiated a gluten-free diet before the gastroduodenal endoscopy. Reduced gluten ingestion from the time of referral to the time of endoscopy might be sufficient to induce alteration in the enterocyte status and the mucosal proteome without affecting intestinal morphology. ${ }^{38}$ Patient P10, who remained M3B after treatment, also recovered some expression of enterocyte-derived proteins, albeit at lower level than patients recovering to M0-1 (Figure 2B). This suggests increased enterocyte maturation despite incomplete histologic recovery. In contrast to other enterocyte-derived proteins, epithelial splicing regulatory protein 1, an epithelial-specific splicing regulator, was found to be overall higher expressed in UCD compared with TCD. This may be because of the increased proliferation and differentiation of enterocytes in UCD. Overall, these data support the notion that enterocyte maturation and function, as assessed on the protein level, can distinguish between TCD and UCD in cases of incomplete histologic recovery.

\section{Processes Related to Immune Response and Plasma Cell Function Dominate in UCD Mucosa}

The 175 proteins with increased expression in UCD were assigned to 152 unique genes for GO biological process enrichment analysis (Supplemental Table S2). Enrichment of several immune response processes, such as defense responses, antigen processing, and presentation, and B-cell activation were found (Figure 3A). Processes related to endoplasmic reticulum stress and response to endoplasmic reticulum stress were also enriched. These likely reflect the massive protein synthesis machinery that operates in plasma cells, which are abundant in the celiac lesion. Proteins annotated to the enriched processes are listed in Supplemental Table S4.

\section{Differentiation of UCD and TCD on the Basis of Ig Gene Family Expression}

A large proportion of the plasma cells in UCD produce disease-specific antibodies targeting TG2 or deamidated 


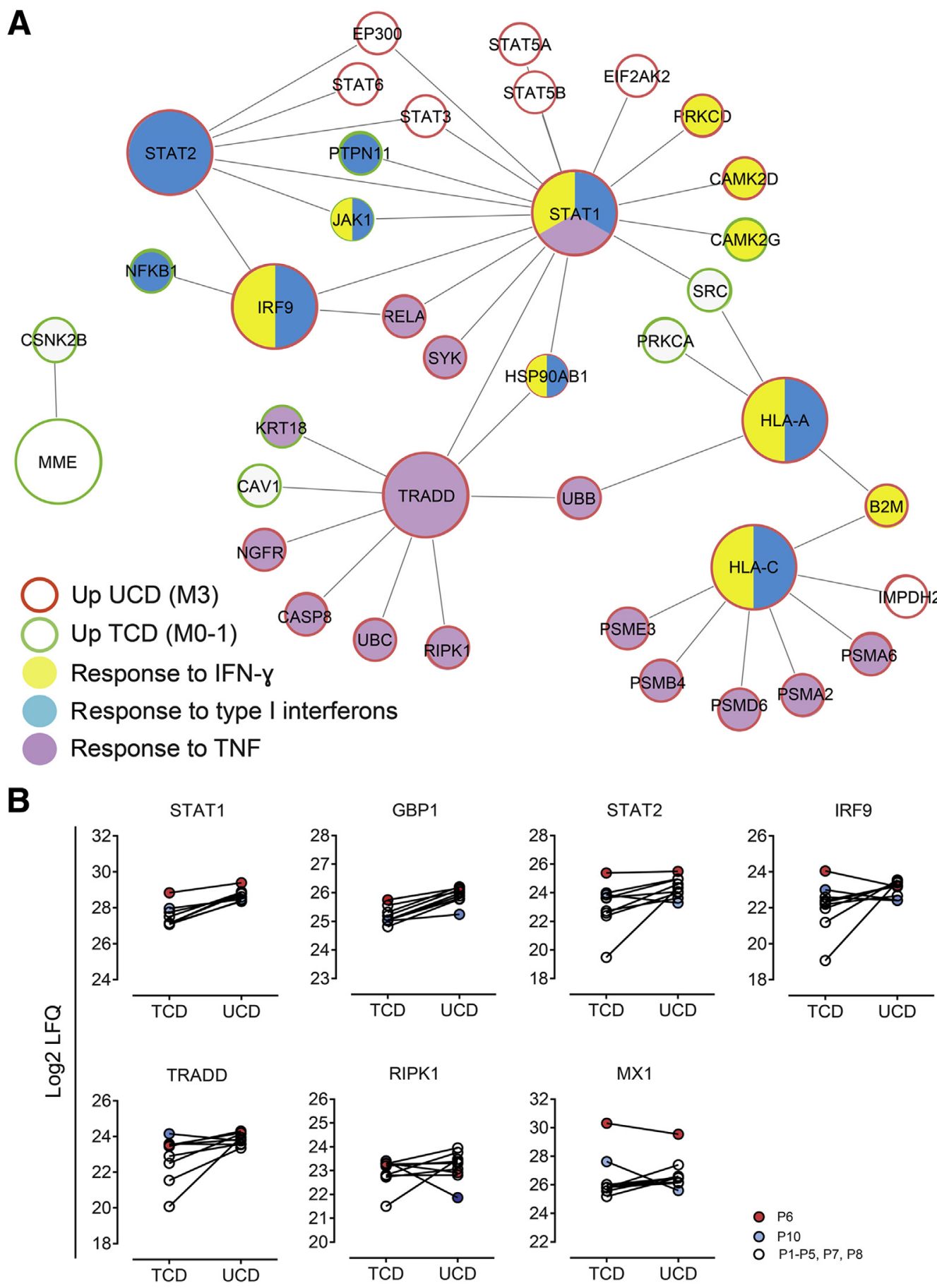

Figure 5 Protein-protein interaction (PPI) analysis reveals dominant cytokine responses. A: Protein interaction network filtered on response to cytokine, as described in Materials and Methods. All identified proteins were considered for PPI analysis and filtered on the basis of response to cytokine. $t$-Test significant proteins are shown as large nodes, and node border indicated higher expression in untreated celiac disease (UCD; red) or treated celiac disease (TCD; green). Nodes were further colored according to the presence in three selected Gene Ontology terms; other proteins are colored gray. B: Comparison of log2-transformed LFQ intensities for selected proteins central to the cytokine responses. P, patient.

gluten. Antibody responses to both antigens show stereotyped and biased use of Ig variable region genes. ${ }^{11,39-41}$ Many proteins in the data set were derived from identification of Ig fragments. Variable region Ig sequences are incompletely covered and poorly annotated in the Uniprot database. Thus, to address whether Ig gene family use could be assessed from the data, a dedicated Ig sequence database based on International ImMunoGeneTics Information 
A

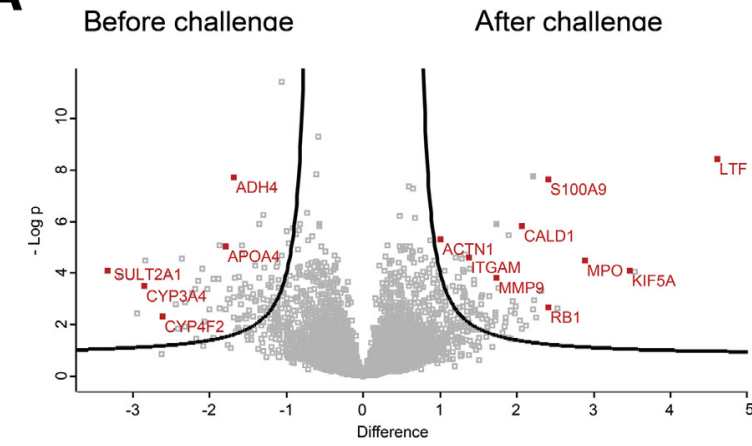

B

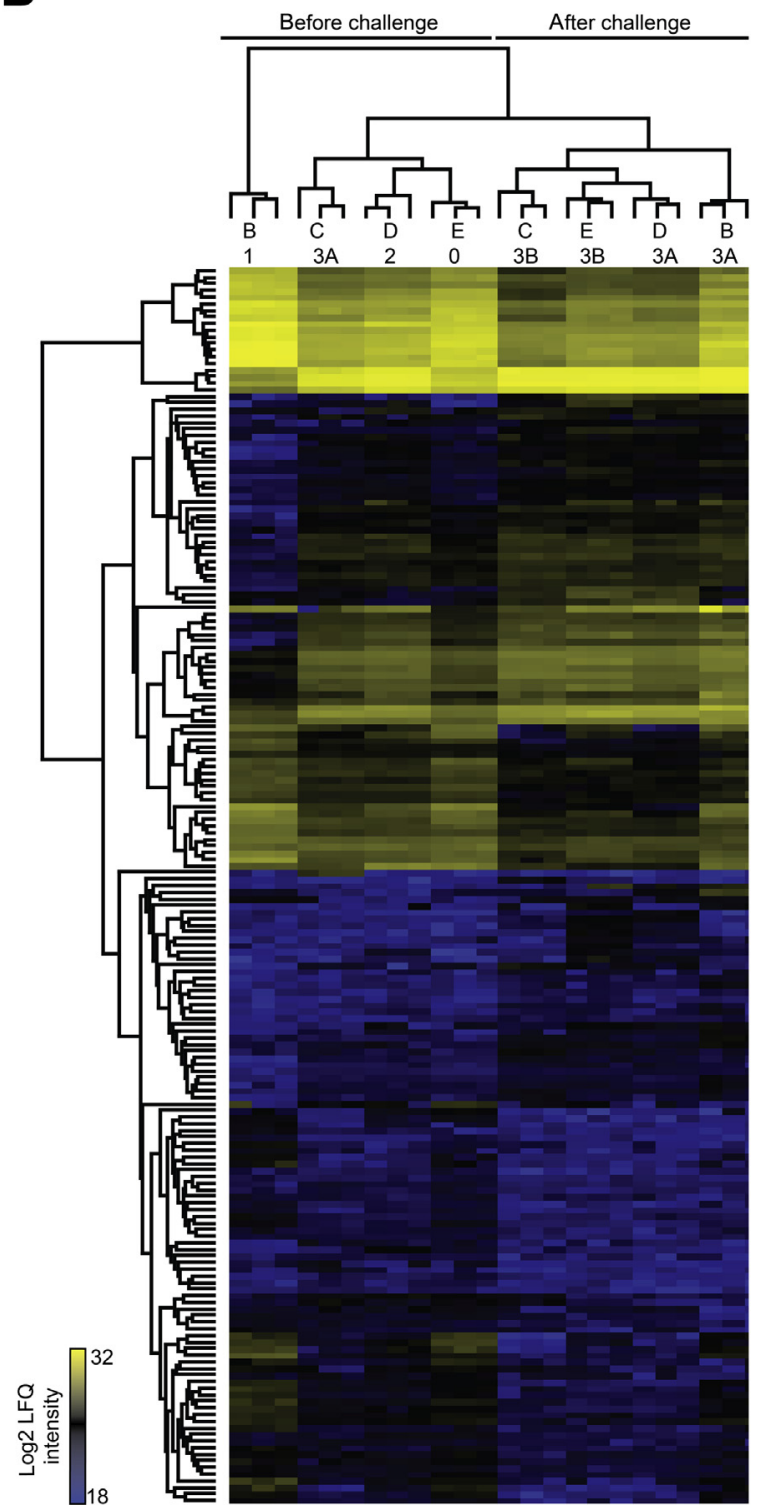

Figure 6 Differential protein expression in treated celiac disease (TCD) patients before and after a 3-day gluten challenge. A: Differentially expressed proteins in mucosa of TCD patients before (day 0 ) or after a 3-day gluten challenge (day 4) visualized by volcano plot (two-sample $t$-test, false-discovery rate $<0.05$, S0 $=0.5$ ). Selected proteins are shown in red. B: Hierarchical clustering of log2-transformed LFQ intensities of differentially expressed proteins will group samples as before or after gluten challenge (yellow $=32$, and blue $=18$ ).
System sequences was searched against. LFQ normalization was found to be equivalent to the Uniprot-derived data set (Supplemental Figure S2). After filtering, 42 Ig gene family members, including 34 variable region families, were identified (Supplemental Table S5). Principal component analysis of $\log 2$ transformed LFQ intensities separated UCD from TCD samples (Figure 3, B and C). The vast majority of identified Ig sequences showed increased expression in UCD compared with TCD (two-sample $t$-test false-discovery rate $<0.05$ ) (Figure 3D). In particular, three Ig variable regions separated UCD from TCD on the basis of fold change in expression (IGKV3-15D, IGKV3-11, and IGHV551). Of these three Ig variable regions, only IGHV5-5I decreased consistently in all patients after treatment (except for patient P7) (Figure 3E).

\section{Increased Expression of Proteins Derived from Neutrophils in UCD Mucosa}

Many of proteins with the highest fold increase in UCD compared with TCD mucosa are typically produced by neutrophils (Figure 1C). ClueGo Reactome pathway enrichment analysis showed that 26 of the proteins with increased expression in UCD mapped to the pathway neutrophil degranulation (Figure 4A and Supplemental Table S6). Some of these proteins are, however, also produced by other cells, such as monocytes/macrophages. To address whether this protein signature derives from neutrophils or other cells, neutrophils (CD15-positive cells) (Supplemental Figure S3) and cells expressing two of the differentially expressed proteins [MPO and calprotectin (heterodimer of S1008A/S1009A)] were counted by immunoenzyme staining. Neutrophils were increased in UCD samples, but the degree of infiltration varied between patients (Figure 4B). Neutrophils were low or absent in TCD samples from all patients. The number of cells expressing MPO was comparable to the number of neutrophils and was low in all TCD samples. In contrast, calprotectin staining was observed in many cells in UCD, and positive cells decreased but did not disappear on treatment (TCD). The differences in cell density agree well with the protein expression levels detected by mass spectrometry in these patients (Figure 4C). To better address which cells contribute to the protein signal observed by mass spectrometry, cells were analyzed by immunofluorescence for expression of CD15 (neutrophils), CD163 (macrophages), and MPO or calprotectin (Figure 4D). Neutrophils showed strong staining for both MPO and calprotectin. Few MPO-positive cells were observed that were not neutrophils. In contrast, calprotectin staining was observed in other cells, including TCD samples in which neutrophils were absent. Some of the calprotectin-positive cells also stained weakly for CD163, indicating that these cells have a myeloid origin. From these data, it can be concluded that many of the differentially expressed proteins detected by mass spectrometry primarily derive from 

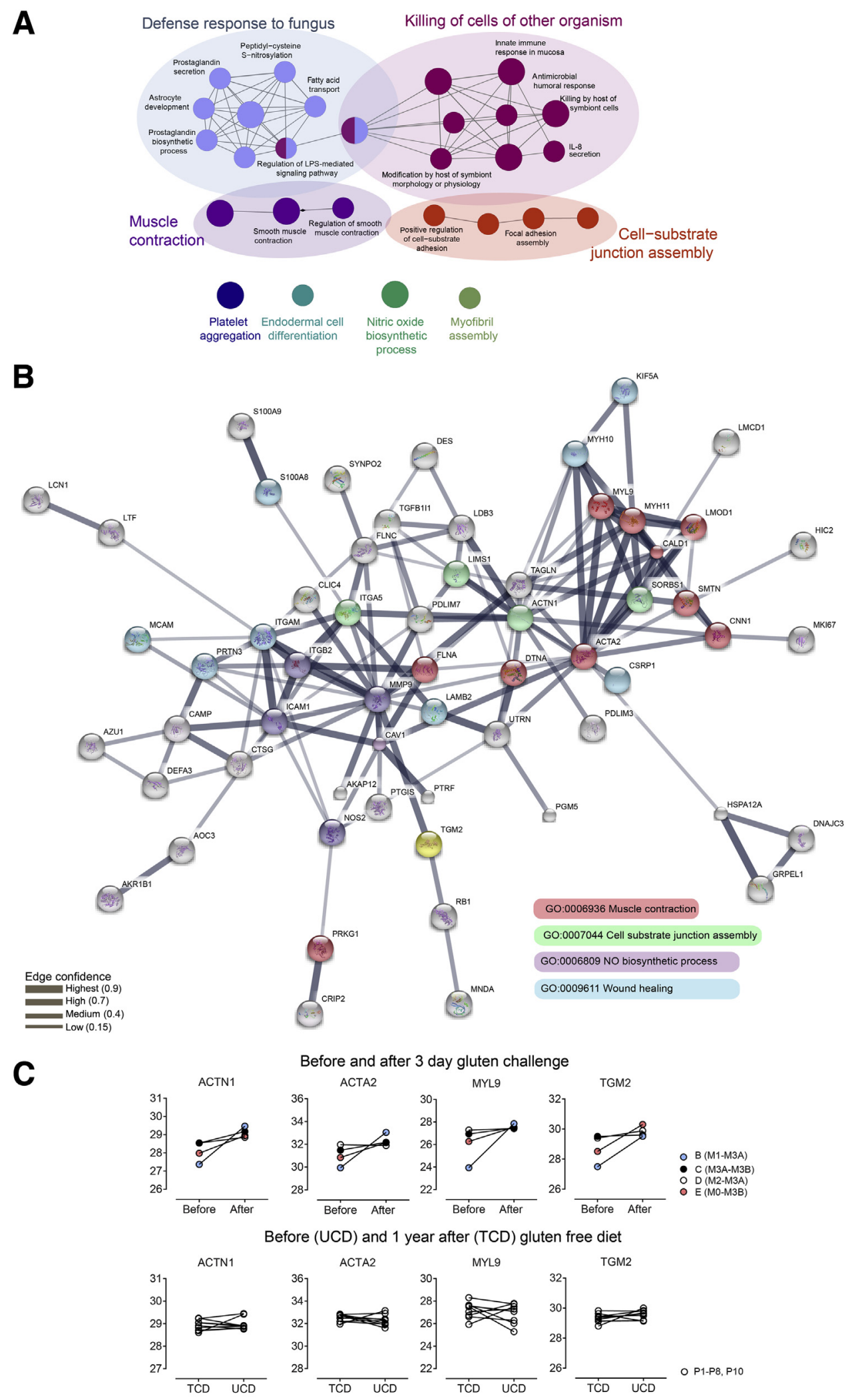

Figure 7 Proteins involved in tissue remodeling are up-regulated in response to gluten challenge. A: Gene Ontology (G0) biological process enrichment analysis of proteins significantly up-regulated after 3-day gluten challenge. B: STRING protein-protein interaction analysis of significantly increased proteins results in 135 protein-protein interactions (edges). Selected proteins are manually color coded to show occurrence in enriched GO biological process, as shown in $\mathbf{A}$, in addition to the GO term wound healing. Transglutaminase 2 (TGM2) is indicated in yellow. C: Comparison of log2-transformed LFQ intensities for selected proteins involved in tissue remodeling and the autoantigen TGM2 for patients before and after 3-day challenge, and patients P1 to P8 and P10 UCD versus TCD. 
neutrophils in UCD, but that some proteins, like calprotecin, can to some degree also derive from monocytes/ macrophages.

\section{Response to Cytokines in UCD Mucosa}

Gluten-specific effector $\mathrm{CD} 4^{+} \mathrm{T}$ cells are crucial for the pathogenesis of $\mathrm{CD}$. These cells are low in total number in the celiac lesion but exert their actions through secretion of proinflammatory cytokines. ${ }^{42}$ Cytokines themselves are rarely detected in tissue proteome studies using mass spectrometry. ${ }^{43}$ Identification of cytokine involvement therefore relies on detection of downstream effects. Among the biological processes enriched in UCD mucosa, both IFN- $\gamma-$ mediated signaling pathway and type I interferon signaling pathway were seen (Figure $3 \mathrm{~A}$ and Supplemental Table S4). For the ClueGo enrichment analysis, only the $t$-test significant proteins were considered. To address if additional proteins involved in response to cytokines could be detected in the data set, a PPI analysis was performed in which all identified proteins were considered. The $t$-test significant proteins were used as seeds to build the network, which was then filtered to only include proteins annotated the GO term response to cytokine. All proteins were categorized as up- or down-regulated on the basis of their fold change in expression, irrespective of $t$-test significance. From this network, it can be seen that most interacting proteins in the data set that are part of response to cytokines are found in the GO terms response to type I interferon, response to IFN- $\gamma$, or response to tumor necrosis factor (Figure 5A). Most of these proteins showed higher expression in UCD mucosa compared with TCD mucosa. Several of the most differentially expressed proteins (eg, STAT1) are shared between these cytokine responses. However, cytokine-specific responses are transmitted by generation of different protein complexes: type I interferon signaling is mediated by the trimeric complex of STAT1, STAT2, and IRF9, whereas IFN- $\gamma$ signaling is mediated by STAT1 homodimers. ${ }^{44}$ From the LFQ intensities, STAT1 and the IFN- $\gamma$-induced protein GBP1 were more abundant than STAT2 and IRF9, which may suggest that response to IFN- $\gamma$ dominates over response to type I interferon (Figure 5B). Tumor necrosis factor response proteins TRADD and RIPK1 were also less abundant than GBP1. Most patients showed reduced expression of these proteins after treatment, with the exception of patients P6 and P10 (Figure 5B). Although STAT1 and GBP1 expression decreased, both patients showed increased expression of STAT2, IRF9, TRADD, and RIPK after treatment. P6 also showed aberrantly high expression of MX1, and MX1 expression increased in both patients after treatment. These data suggest that the UCD patients show decreased IFN- $\gamma$ signaling after treatment. In addition, two of the patients displayed protein expression patterns indicative of an ongoing type I interferon response, independent of dietary gluten.

\section{Characterization of M3 Mucosa in Response to Short-} Term Oral Gluten Challenge

The M3 lesion of CD patients at the time of diagnosis has typically developed over time. It hence represents a state of chronic inflammation that may not provide information about the initial changes that occur on remodeling in response to dietary gluten. On reintroduction of gluten, TCD patients can develop morphologic changes within weeks and in some cases also within a few days. ${ }^{45-48}$ Short term (3-day) oral gluten challenge is sufficient to recruit diseasespecific $T$ cells to the blood on day 6 , as detected by flow cytometry, and some patients also develop clear morphologic changes in the intestine on day 4 after initiation of challenge. ${ }^{49-51}$ This could be considered an early stage of M3 lesion that is likely to differ from the M3 lesion of UCD patients, despite identical histologic classification. Biopsy material from four TCD patients who all developed morphologic changes on day 4 in response to 3-day gluten challenge was analyzed (Table 2). ${ }^{50}$ Comparing biopsy specimens collected before (day 0) and after (day 4) gluten challenge in total, 4474 proteins were identified, where 187 proteins were differentially expressed (88 proteins with increased expression and 99 proteins with decreased expression on day 4; two-sample $t$-test, false-discovery rate $<0.05$ ) (Figure 6A and Supplemental Tables S7 and S8). Hierarchical clustering of $\log 2$-transformed LFQ intensities of the differentially expressed proteins showed that the samples cluster as before or after gluten challenge (Figure 6B). Similar to UCD M3 mucosa, reduced expression of enterocyte-derived proteins and increased expression of neutrophil- and monocyte-derived proteins were observed on day 4 after gluten challenge (Figure 6A). Both neutrophil- and monocyte-derived cells have previously been shown to increase on day 4 in this patient cohort. ${ }^{52}$ By contrast, proteins hallmarking plasma cells were not markedly increased on day 4 (data not shown).

\section{Short-Term Gluten Challenge Induces Inflammation, Tissue Remodeling, and Wound Healing Processes}

GO biological process analysis of 85 unique genes from 88 proteins with increased expression on day 4 showed enrichment for processes related to acute inflammation, tissue organization, and remodeling (Figure 7A). This includes innate defense responses, muscle contraction, and cell-substrate junction assembly (Supplemental Table S9). Notably, most proteins with increased expression after gluten challenge interact with each other, as determined by STRING protein-protein interaction analysis, suggesting that they are coregulated and part of a coordinated tissue response (Figure 7B). Most of these proteins showed increased expression in all four patients on day 4, irrespective of Marsh score on day 0 , although the biggest change was observed for patients $\mathrm{B}$ and $\mathrm{E}$, who progressed from M0-1 to M3A-B (Figure 7C). Also, the CD 
autoantigen TG2 was up-regulated in three of four patients in response to 3-day gluten challenge (Figure 7C). In contrast, these proteins did not decrease in response to treatment in patients P1 to P10 (Figure 7C). Thus, global proteome analysis of biopsy specimens collected shortly after gluten exposure captures the early phases of tissue remodeling in the celiac small intestine.

\section{Discussion}

This study represents the first global proteomics characterization of the celiac small intestine by use of label-free quantitative mass spectrometry. Changes in proteome expression after removal or reintroduction of gluten were compared, using material from FFPE small intestinal biopsy specimens collected for histology assessment. This study demonstrates that such material can be used to characterize and stratify diseased tissue on the protein level. Differential expression of proteins that corroborate known features of $\mathrm{CD}$, such as loss of mature enterocytes, response to cytokines, and abundance of plasma cells, was found. In several patients, differential expression of canonical neutrophilderived proteins was also seen. Expression of IGHV5-51, the variable gene used by epitope 1 anti-TG2 autoantibodies, decreased in all patients in response to GFD diet. Protein expression in four patients who developed morphologic changes on day 4 in response to gluten challenge was also compared. Coordinated up-regulation of proteins involved in tissue remodeling and wound response was observed, which shed light on processes that occur early in the intestinal recall response toward gluten.

These data capture many of the canonical features of the immune response of the celiac lesion, in particular the abundance of plasma cells. Notwithstanding, the most differentially expressed proteins in the data sets are typically expressed by neutrophils (eg, MPO, LTF, AZU1, S100A8, and S100A9). Some of these proteins can also be expressed by monocytes/macrophages, which are increased in both UCD and TCD in response to gluten challenge. ${ }^{53}$ The presence of neutrophils in the UCD samples was verified by immunohistochemistry, and it was demonstrated that neutrophils express high amounts of both MPO and calprotectin. Neutrophils were close to absent in TCD patients. Thus, conceivably, the dramatic change in protein expression detected by mass spectrometry reflects neutrophil infiltration. High protein content of stored neutrophil granules may facilitate detection of these proteins so that relatively few cells are required to give a strong protein signal. Previously, gene expression studies have shown increased transcript levels of several canonical neutrophil-derived proteins in $\mathrm{CD}$ patients, and neutrophil infiltration has been reported in celiac lesions. ${ }^{21,54,55}$ Collectively, available observations advocate further investigations into the role of neutrophils in the pathogenesis of CD.

Because of their relatively low abundance, cytokines are rarely detected by mass spectrometry analysis of total tissue digests, which is in contrast to mRNA expression studies. Therefore, an assessment of cytokines is better evaluated by expression of their downstream induced proteins. A hallmark of $\mathrm{CD}$ is the accumulation of proinflammatory gluten-reactive $\mathrm{CD} 4^{+} \mathrm{T}$ cells that produce high amounts of IFN $-\gamma$ in the intestinal lesion, in addition to cytokines, such as IL-21 and tumor necrosis factor. ${ }^{15,56}$ These cells are likely necessary, but not sufficient, to cause intestinal remodeling, which may also require innate cytokines, such as IL-15 and type I interferons, to sufficiently disrupt tissue homeostasis and promote enterocyte killing by cytotoxic intraepithelial lymphocytes. ${ }^{7}$ Increased expression of many proteins indicative of active cytokine signaling in UCD, in particular response to IFN- $\gamma$ but also to type I interferon and tumor necrosis factor, was observed. The different expression level of these proteins suggests dominance of IFN- $\gamma$ response over type I interferon, which would agree with previous studies showing lower expression levels and large patient-to-patient variability for type I interferon. ${ }^{57,58}$ Response to IL-15 was not detected by this approach. Notably, patients P6 and P10 displayed protein expression patterns indicative of an ongoing type I interferon response independently of dietary gluten, and P6 showed unusually high expression of MX1 both at the time of diagnosis and after treatment.

Identification of noninvasive markers to monitor intestinal recovery and diet adherence in CD is important because it can eliminate the need for biopsy evaluation in the followup of patients after diagnosis. Proteins that were found to have higher expression in TCD versus UCD mucosa can potentially serve as such markers. Most of these proteins derive from enterocytes. The highest fold change in expression was observed for the enzymes CYP3A4, CYP2C9, and LCT, followed by proteins involved in cellular metabolism and enterocyte structure (eg, scinderin and espin, which are important for microvilli formation). Enzymes are good biomarker candidates because assessment of their activity can serve as a measure of enterocyte vitality. This has already been explored in human subjects for CYP3A4 by monitoring oral bioavailability of simvastatin, which is predominantly metabolized by intestinal CYP3A $4{ }^{59,60}$ Indeed, simvastatin was found to have high oral bioavailability in UCD patients, reflecting lower CYP3A4 activity. ${ }^{60}$ From these data, CYP2C9 emerges as a candidate marker. Both CYP2C9 and LCT can distinguish between most UCD samples and patients P7 and P8, who were found to differ from the remaining UCD patients. Analysis of expression of these enzymes can possibly be superior to CYP3A4 monitoring for stratification of UCD patients, but their expression pattern must first be verified in larger patient cohorts. Enterocyte damage can also be monitored by measuring FABP2 protein in serum and urine. ${ }^{61}$ Both retrospective and prospective studies have shown correlation between serum FABP2 levels, Marsh score, and response to gluten-free diet in CD patients. ${ }^{38,62,63}$ Decreased expression of FABP2 was observed in UCD 
mucosa, which agrees with damage and loss of enterocytes and release of this protein into serum.

Proteins that are overexpressed in UCD may also serve as biomarkers on the basis of their reduced expression in response to treatment. Most of the proteins found to have higher expression in UCD derive from immune response processes in which a change in protein expression can be induced by stimuli other than dietary gluten. In contrast, the autoantibody response toward TG2 is gluten dependent and highly disease specific. Several different Ig sequences were identified from the FFPE material. Of these, IGHV5-51 decreased unanimously after 1 year of treatment (except for patient P7). IGHV5-51 is the canonical heavy chain variable region used by epitope 1 anti-TG2 antibodies, which are found in all untreated CD patients. ${ }^{11,40,41} \mathrm{We}$ propose that IGHV5-5I expression may represent a diseasespecific measure of intestinal immune activation in CD.

Three of the 10 patients who were analyzed before and after GFD showed protein expression patterns that did not correlate with their Marsh classification. Two patients (P7 and $\mathrm{P} 8$ ) were classified as $\mathrm{M} 3 \mathrm{~B}$ at the time of diagnosis (UCD) but were more similar to TCD patients on the protein level. One patient (P10) showed increased expression of several enterocyte-derived proteins, such as CYP3A4, after treatment, despite classification as M3B. Discrepancy between protein expression and histology has previously been noted; in agreement with our observations for P10, CYP3A4 function was reported to increase after treatment, despite incomplete normalization of histology. ${ }^{60}$ This argues that histology alone may be insufficient to assess enterocyte vitality in $\mathrm{CD}$. The global proteomics analysis supports the assessment of enterocyte vitality as measure for intestinal status and recovery in CD. However, further studies should be conducted to evaluate the correlation between enterocyte protein expression, treatment status, and tissue histology.

The four analyzed TCD patients who developed morphologic changes on day 4 after gluten challenge displayed coordinated increase in expression of proteins that reflect rapid tissue remodeling. This expression pattern was not observed in the first patient group, in which UCD was compared with TCD mucosa. Thus, these proteins likely reflect processes that occur soon after gluten challenge. Intriguingly, TG2 expression increased clearly in two of four patients on day 4 after challenge. Further studies are required to determine whether similar changes in protein expression occur in TCD patients who develop less pronounced morphologic changes in response to gluten challenge.

The use of FFPE tissue material has become increasingly popular, in particular for characterization of neoplastic tissue and tumor biomarker discovery but also immunemediated diseases. Such studies are often challenging because of heterogeneity of the patient material and limited knowledge about the underlying pathology. CD represents, in this respect, a unique immune-mediated disease: there is substantial knowledge on the pathologic adaptive immune processes, and exposure to the antigen (gluten) that drives the tissue inflammation can also be controlled. The use of LFQ of protein expression allows for streamlined and simple sample workup, which reduces potential experimental biases and other technical challenges that often arise from traditional label-based quantitative mass spectrometry approaches. We herein show as proof of concept that LFQ of proteins from FFPE tissue sections by use of mass spectrometry allows for accurate characterization of the celiac intestine. By use of archival biopsy material and careful design of patient groups, this method represents a potent tool to decipher specific questions and the missing details of disease pathogenesis.

\section{Acknowledgments}

We thank Margit Brottveit for recruitment of patients; Melinda Ráki for assistance with patient selection; Magnus $\varnothing$. Arntzen for help with the initial steps of data analysis; Rasmus Iversen for providing the Ig sequence database; Maria Stensland for undertaking proteomics analysis; Linda T. Dorg and Ellen Hellesylt for helping out with histochemistry work; and Dr. Inge Dale (Calpro, Oslo, Norway) for providing rabbit polyclonal anti-calprotectin antibody.

\section{Supplemental Data}

Supplemental material for this article can be found at https://doi.org/10.1016/j.ajpath.2018.03.017.

\section{References}

1. Maier T, Guell M, Serrano L: Correlation of mRNA and protein in complex biological samples. FEBS Lett 2009, 583:3966-3973

2. Plotkin JB: Transcriptional regulation is only half the story. Mol Syst Biol 2010, 6:406

3. Matzke MM, Brown JN, Gritsenko MA, Metz TO, Pounds JG, Rodland KD, Shukla AK, Smith RD, Waters KM, McDermott JE, Webb-Robertson BJ: A comparative analysis of computational approaches to relative protein quantification using peptide peak intensities in label-free LC-MS proteomics experiments. Proteomics 2013, 13:493-503

4. Wisniewski JR, Dus K, Mann M: Proteomic workflow for analysis of archival formalin-fixed and paraffin-embedded clinical samples to a depth of 10000 proteins. Proteomics Clin Appl 2013, 7:225-233

5. Steiner C, Ducret A, Tille JC, Thomas M, McKee TA, RubbiaBrandt L, Scherl A, Lescuyer P, Cutler P: Applications of mass spectrometry for quantitative protein analysis in formalin-fixed paraffin-embedded tissues. Proteomics 2014, 14:441-451

6. Gustafsson OJ, Arentz G, Hoffmann P: Proteomic developments in the analysis of formalin-fixed tissue. Biochim Biophys Acta 2015, 1854:559-580

7. Sollid LM, Jabri B: Triggers and drivers of autoimmunity: lessons from coeliac disease. Nat Rev Immunol 2013, 13:294-302

8. Douglas AP, Crabbe PA, Hobbs JR: Immunochemical studies on the serum, intestinal secretions and intestinal mucosa in patients with adult celiac disease and other forms of the celiac syndrome. Gastroenterology 1970, 59:414-425 
9. Baklien K, Brandtzaeg P, Fausa O: Immunoglobulins in jejunal mucosa and serum from patients with adult coeliac disease. Scand J Gastroenterol 1977, 12:149-159

10. Scott H, Ek J, Baklien K, Brandtzaeg P: Immunoglobulin-producing cells in jejunal mucosa of children with coeliac disease on a glutenfree diet and after gluten challenge. Scand J Gastroenterol 1980, $15: 81-88$

11. Di Niro R, Mesin L, Zheng NY, Stamnaes J, Morrissey M, Lee JH, Huang M, Iversen R, du Pre MF, Qiao SW, Lundin KE, Wilson PC, Sollid LM: High abundance of plasma cells secreting transglutaminase 2-specific IgA autoantibodies with limited somatic hypermutation in celiac disease intestinal lesions. Nat Med 2012, 18: 441-445

12. Molberg O, McAdam SN, Korner R, Quarsten H, Kristiansen C, Madsen L, Fugger L, Scott H, Noren O, Roepstorff P, Lundin KE, Sjostrom H, Sollid LM: Tissue transglutaminase selectively modifies gliadin peptides that are recognized by gut-derived $\mathrm{T}$ cells in celiac disease. Nat Med 1998, 4:713-717

13. Dorum S, Arntzen MO, Qiao SW, Holm A, Koehler CJ, Thiede B, Sollid LM, Fleckenstein B: The preferred substrates for transglutaminase 2 in a complex wheat gluten digest are peptide fragments harboring celiac disease T-cell epitopes. PLoS One 2010, 5:e14056

14. Lundin KE, Scott H, Hansen T, Paulsen G, Halstensen TS, Fausa O, Thorsby E, Sollid LM: Gliadin-specific, HLA$\mathrm{DQ}(\alpha 1 * 0501, \beta 1 * 0201)$ restricted T cells isolated from the small intestinal mucosa of celiac disease patients. J Exp Med 1993, 178: 187-196

15. Bodd M, Raki M, Tollefsen S, Fallang LE, Bergseng E, Lundin KE, Sollid LM: HLA-DQ2-restricted gluten-reactive T cells produce IL-21 but not IL-17 or IL-22. Mucosal Immunol 2010, 3:594-601

16. Molberg O, Kett K, Scott H, Thorsby E, Sollid LM, Lundin KE: Gliadin specific, HLA DQ2-restricted T cells are commonly found in small intestinal biopsies from coeliac disease patients, but not from controls. Scand J Immunol 1997, 46:103-109

17. Meresse B, Chen Z, Ciszewski C, Tretiakova M, Bhagat G, Krausz TN, Raulet DH, Lanier LL, Groh V, Spies T, Ebert EC, Green PH, Jabri B: Coordinated induction by IL15 of a TCRindependent NKG2D signaling pathway converts CTL into lymphokine-activated killer cells in celiac disease. Immunity 2004, 21:357-366

18. Oberhuber G: Histopathology of celiac disease. Biomed Pharmacother 2000, 54:368-372

19. Haere P, Hoie O, Schulz T, Schonhardt I, Raki M, Lundin KE: Longterm mucosal recovery and healing in celiac disease is the rule: not the exception. Scand J Gastroenterol 2016, 51:1439-1446

20. Bragde H, Jansson U, Jarlsfelt I, Soderman J: Gene expression profiling of duodenal biopsies discriminates celiac disease mucosa from normal mucosa. Pediatr Res 2011, 69:530-537

21. Diosdado B, van Bakel H, Strengman E, Franke L, van Oort E, Mulder CJ, Wijmenga C, Wapenaar MC: Neutrophil recruitment and barrier impairment in celiac disease: a genomic study. Clin Gastroenterol Hepatol 2007, 5:574-581

22. Simula MP, Cannizzaro R, Canzonieri V, Pavan A, Maiero S, Toffoli G, De Re V: PPAR signaling pathway and cancer-related proteins are involved in celiac disease-associated tissue damage. Mol Med 2010, 16:199-209

23. Brottveit M, Beitnes AC, Tollefsen S, Bratlie JE, Jahnsen FL, Johansen FE, Sollid LM, Lundin KE: Mucosal cytokine response after short-term gluten challenge in celiac disease and non-celiac gluten sensitivity. Am J Gastroenterol 2013, 108:842-850

24. Cox J, Mann M: MaxQuant enables high peptide identification rates, individualized p.p.b.-range mass accuracies and proteome-wide protein quantification. Nat Biotechnol 2008, 26:1367-1372

25. Cox J, Neuhauser N, Michalski A, Scheltema RA, Olsen JV, Mann M: Andromeda: a peptide search engine integrated into the MaxQuant environment. J Proteome Res 2011, 10:1794-1805
26. Lefranc MP, Giudicelli V, Ginestoux C, Bodmer J, Muller W, Bontrop R, Lemaitre M, Malik A, Barbie V, Chaume D: IMGT, the international ImMunoGeneTics database. Nucleic Acids Res 1999, 27:209-212

27. Iversen R, Snir O, Stensland M, Kroll JE, Steinsbo O, KorponaySzabo IR, Lundin KEA, de Souza GA, Sollid LM: Strong clonal relatedness between serum and gut IgA despite different plasma cell origins. Cell Rep 2017, 20:2357-2367

28. Vizcaino JA, Csordas A, del-Toro N, Dianes JA, Griss J, Lavidas I, Mayer G, Perez-Riverol Y, Reisinger F, Ternent T, Xu QW, Wang R, Hermjakob H: 2016 Update of the PRIDE database and its related tools. Nucleic Acids Res 2016, 44:D447-D456

29. Deeb SJ, D'Souza RC, Cox J, Schmidt-Supprian M, Mann M: SuperSILAC allows classification of diffuse large B-cell lymphoma subtypes by their protein expression profiles. Mol Cell Proteomics 2012, 11:77-89

30. Shannon P, Markiel A, Ozier O, Baliga NS, Wang JT, Ramage D, Amin N, Schwikowski B, Ideker T: Cytoscape: a software environment for integrated models of biomolecular interaction networks. Genome Res 2003, 13:2498-2504

31. Bindea G, Mlecnik B, Hackl H, Charoentong P, Tosolini M, Kirilovsky A, Fridman WH, Pages F, Trajanoski Z, Galon J: ClueGO: a cytoscape plug-in to decipher functionally grouped gene ontology and pathway annotation networks. Bioinformatics 2009, 25: 1091-1093

32. Razick S, Magklaras G, Donaldson IM: iRefIndex: a consolidated protein interaction database with provenance. BMC Bioinformatics 2008, 9:405

33. Szklarczyk D, Franceschini A, Wyder S, Forslund K, Heller D, Huerta-Cepas J, Simonovic M, Roth A, Santos A, Tsafou KP, Kuhn M, Bork P, Jensen LJ, von Mering C: STRING v10: proteinprotein interaction networks, integrated over the tree of life. Nucleic Acids Res 2015, 43:D447-D452

34. Bankhead P, Loughrey MB, Fernandez JA, Dombrowski Y, McArt DG, Dunne PD, McQuaid S, Gray RT, Murray LJ, Coleman HG, James JA, Salto-Tellez M, Hamilton PW: QuPath: open source software for digital pathology image analysis. Sci Rep 2017, 7:16878

35. Schneider CA, Rasband WS, Eliceiri KW: NIH Image to ImageJ: 25 years of image analysis. Nat Methods 2012, 9:671-675

36. Schindelin J, Arganda-Carreras I, Frise E, Kaynig V, Longair M, Pietzsch T, Preibisch S, Rueden C, Saalfeld S, Schmid B, Tinevez JY, White DJ, Hartenstein V, Eliceiri K, Tomancak P, Cardona A: Fiji: an open-source platform for biological-image analysis. Nat Methods 2012, 9:676-682

37. Cox J, Hein MY, Luber CA, Paron I, Nagaraj N, Mann M: Accurate proteome-wide label-free quantification by delayed normalization and maximal peptide ratio extraction, termed MaxLFQ. Mol Cell Proteomics 2014, 13:2513-2526

38. Adriaanse MPM, Mubarak A, Riedl RG, Ten Kate FJW, Damoiseaux J, Buurman WA, Houwen RHJ, Vreugdenhil ACE; Celiac Disease Study Group: Progress towards non-invasive diagnosis and follow-up of celiac disease in children: a prospective multicentre study to the usefulness of plasma I-FABP. Sci Rep 2017, $7: 8671$

39. Steinsbo O, Henry Dunand CJ, Huang M, Mesin L, SalgadoFerrer M, Lundin KE, Jahnsen J, Wilson PC, Sollid LM: Restricted $\mathrm{VH} / \mathrm{VL}$ usage and limited mutations in gluten-specific IgA of coeliac disease lesion plasma cells. Nat Commun 2014, 5:4041

40. Snir O, Mesin L, Gidoni M, Lundin KE, Yaari G, Sollid LM: Analysis of celiac disease autoreactive gut plasma cells and their corresponding memory compartment in peripheral blood using highthroughput sequencing. J Immunol 2015, 194:5703-5712

41. Roy B, Neumann RS, Snir O, Iversen R, Sandve GK, Lundin KEA, Sollid LM: High-throughput single-cell analysis of B cell receptor usage among autoantigen-specific plasma cells in celiac disease. J Immunol 2017, 199:782-791 
42. Bodd M, Raki M, Bergseng E, Jahnsen J, Lundin KE, Sollid LM: Direct cloning and tetramer staining to measure the frequency of intestinal gluten-reactive $\mathrm{T}$ cells in celiac disease. Eur J Immunol 2013, 43:2605-2612

43. Wilhelm M, Schlegl J, Hahne H, Gholami AM, Lieberenz M, Savitski MM, Ziegler E, Butzmann L, Gessulat S, Marx H, Mathieson T, Lemeer S, Schnatbaum K, Reimer U, Wenschuh H, Mollenhauer M, Slotta-Huspenina J, Boese JH, Bantscheff M, Gerstmair A, Faerber F, Kuster B: Mass-spectrometry-based draft of the human proteome. Nature 2014, 509:582-587

44. Platanias LC: Mechanisms of type-I- and type-II-interferon-mediated signalling. Nat Rev Immunol 2005, 5:375-386

45. Shiner M: Ultrastructural changes suggestive of immune reactions in the jejunal mucosa of coeliac children following gluten challenge. Gut 1973, 14:1-12

46. Shiner M, Ballard J: Antigen-antibody reactions in jejunal mucosa in childhood coeliac disease after gluten challenge. Lancet 1972, 1: $1202-1205$

47. Lancaster-Smith M, Packer S, Kumar PJ, Harries JT: Immunological phenomena in the jejunum and serum after reintroduction of dietary gluten in children with treated coeliac disease. J Clin Pathol 1976, 29: 592-597

48. Sarna VK, Skodje GI, Reims HM, Risnes LF, Dahal-Koirala S, Sollid LM, Lundin KEA: HLA-DQ:gluten tetramer test in blood gives better detection of coeliac patients than biopsy after 14-day gluten challenge. Gut 2017, [Epub ahead of print] doi:10.1136/gutjnl-2017-314461

49. Raki M, Fallang LE, Brottveit M, Bergseng E, Quarsten H, Lundin KE, Sollid LM: Tetramer visualization of gut-homing glutenspecific T cells in the peripheral blood of celiac disease patients. Proc Natl Acad Sci U S A 2007, 104:2831-2836

50. Brottveit M, Raki M, Bergseng E, Fallang LE, Simonsen B, Lovik A, Larsen S, Loberg EM, Jahnsen FL, Sollid LM, Lundin KE: Assessing possible celiac disease by an HLA-DQ2-gliadin Tetramer Test. Am J Gastroenterol 2011, 106:1318-1324

51. Han A, Newell EW, Glanville J, Fernandez-Becker N, Khosla C, Chien YH, Davis MM: Dietary gluten triggers concomitant activation of CD4 + and CD8 $+\alpha \beta$ T cells and $\gamma \delta$ T cells in celiac disease. Proc Natl Acad Sci U S A 2013, 110:13073-13078

52. Beitnes AC, Raki M, Brottveit M, Lundin KE, Jahnsen FL, Sollid LM: Rapid accumulation of CD14+CD11c+ dendritic cells in gut mucosa of celiac disease after in vivo gluten challenge. PLoS One 2012, 7:e33556

53. Beitnes AC, Raki M, Lundin KE, Jahnsen J, Sollid LM, Jahnsen FL: Density of CD163+ CD11c+ dendritic cells increases and CD103+ dendritic cells decreases in the coeliac lesion. Scand J Immunol 2011, 74:186-194
54. Hallgren R, Colombel JF, Dahl R, Fredens K, Kruse A, Jacobsen NO, Venge P, Rambaud JC: Neutrophil and eosinophil involvement of the small bowel in patients with celiac disease and Crohn's disease: studies on the secretion rate and immunohistochemical localization of granulocyte granule constituents. Am J Med 1989, 86:56-64

55. Moran CJ, Kolman OK, Russell GJ, Brown IS, Mino-Kenudson M: Neutrophilic infiltration in gluten-sensitive enteropathy is neither uncommon nor insignificant: assessment of duodenal biopsies from 267 pediatric and adult patients. Am J Surg Pathol 2012, 36: $1339-1345$

56. Nilsen EM, Lundin KE, Krajci P, Scott H, Sollid LM, Brandtzaeg P: Gluten specific, HLA-DQ restricted $\mathrm{T}$ cells from coeliac mucosa produce cytokines with Th1 or Th0 profile dominated by interferon gamma. Gut 1995, 37:766-776

57. Monteleone G, Pender SL, Alstead E, Hauer AC, Lionetti P, McKenzie C, MacDonald TT: Role of interferon alpha in promoting $\mathrm{T}$ helper cell type 1 responses in the small intestine in coeliac disease. Gut 2001, 48:425-429

58. Raki M, Beitnes AC, Lundin KE, Jahnsen J, Jahnsen FL, Sollid LM: Plasmacytoid dendritic cells are scarcely represented in the human gut mucosa and are not recruited to the celiac lesion. Mucosal Immunol 2013, 6:985-992

59. Lilja JJ, Kivisto KT, Neuvonen PJ: Grapefruit juice-simvastatin interaction: effect on serum concentrations of simvastatin, simvastatin acid, and HMG-CoA reductase inhibitors. Clin Pharmacol Ther 1998, 64:477-483

60. Moron B, Verma AK, Das P, Taavela J, Dafik L, Diraimondo TR, Albertelli MA, Kraemer T, Maki M, Khosla C, Rogler G, Makharia GK: CYP3A4-catalyzed simvastatin metabolism as a noninvasive marker of small intestinal health in celiac disease. Am J Gastroenterol 2013, 108:1344-1351

61. Derikx JP, Vreugdenhil AC, Van den Neucker AM, Grootjans J, van Bijnen AA, Damoiseaux JG, van Heurn LW, Heineman E, Buurman WA: A pilot study on the noninvasive evaluation of intestinal damage in celiac disease using I-FABP and L-FABP. J Clin Gastroenterol 2009, 43:727-733

62. Adriaanse MP, Tack GJ, Passos VL, Damoiseaux JG, Schreurs MW, van Wijck K, Riedl RG, Masclee AA, Buurman WA, Mulder CJ, Vreugdenhil AC: Serum I-FABP as marker for enterocyte damage in coeliac disease and its relation to villous atrophy and circulating autoantibodies. Aliment Pharmacol Ther 2013, 37:482-490

63. Adriaanse MP, Leffler DA, Kelly CP, Schuppan D, Najarian RM, Goldsmith JD, Buurman WA, Vreugdenhil AC: Serum I-FABP detects gluten responsiveness in adult celiac disease patients on a short-term gluten challenge. Am J Gastroenterol 2016, 111: $1014-1022$ 